\title{
Location and variation of the summertime upper-troposphere temperature maximum over South Asia
}

\author{
Guoxiong Wu $\cdot$ Bian He $\cdot$ Yimin Liu $\cdot$ Qing Bao $\cdot$ \\ Rongcai Ren
}

Received: 16 January 2015 / Accepted: 30 January 2015 / Published online: 3 March 2015

(C) The Author(s) 2015. This article is published with open access at Springerlink.com

\begin{abstract}
The upper-troposphere-temperature-maximum (UTTM) over South Asia is a pronounced feature in the Northern Hemisphere summer. Its formation mechanism is still unclear. This study shows that the latitude location of the upper-tropospheric warm-center $(\boldsymbol{T})$ coincides with the subtropical anticyclone, and its longitude location is determined by the zonal distribution of vertical gradient of heating/cooling $\left(\boldsymbol{Q}_{z}=\partial \boldsymbol{Q} / \partial \boldsymbol{z}\right)$, which is different from the Gill's model. Since both convective heating and radiation cooling decrease with height in the upper troposphere, the heating/ cooling generates vertical northerly/southerly shear, leading to a warm/cold center being developed between heating in the east/west and cooling in the west/east. The location of the UTTM coincides with the South Asian High (SAH) and is between a radiation cooling in the west and the Asian-monsoon convection heating source in the east. The UTTM is sensitive to this convective heating: increased heating in the source region in a general circulation model causes intensification of both the SAH and UTTM, and imposing periodic convective heating there results in oscillations in the SAH, UTTM, and vertical motion to the west with the same period. Diagnoses of reanalysis indicate that such an inherent subtropical $\boldsymbol{T}-\boldsymbol{Q}_{\boldsymbol{Z}}$ relation is significant at
\end{abstract}

G. Wu $\cdot$ B. He $(\bowtie) \cdot$ Y. Liu $(\bowtie) \cdot$ Q. Bao $\cdot$ R. Ren

State Key Lab of Atmospheric Sciences and Geophysical Fluid Dynamics (LASG), Institute of Atmospheric Physics, Chinese Academy of Sciences, Beijing 100029, China

e-mail: heb@lasg.iap.ac.cn

Y. Liu

e-mail: lym@lasg.iap.ac.cn

B. He

State Key Laboratory of Loess and Quaternary Geology, Institute of Earth Environment, Chinese Academy of Sciences, Xi' an, China interannual timescale. During the end of the twentieth century, rainfall increase over South China is accompanied by an increasing northerly flow aloft and intensification in the SAH and UTTM to the west. Results demonstrate that the feedback of atmospheric circulation to rainfall anomalies is an important contributor to the regional climate anomaly pattern.

Keywords Upper-troposphere temperature maximum (UTTM) · Feedback between rainfall and circulation · Temperature-vertical heating gradient $\left(\boldsymbol{T}-\boldsymbol{Q}_{Z}\right)$ relation

\section{Introduction}

In the boreal summer half of the year there exists in the upper troposphere of the Eurasian subtropics a huge high pressure system centered over South Asia southwest of the Tibetan Plateau (TP), which was formerly known as the Tibetan High (Ye and Gao 1979) but is now referred to more frequently as the South Asian High (SAH). The center of the climate mean SAH first appears in April over the South China Sea (SCS) before the onset of the Asian summer monsoon (ASM) (Liu et al. 2012a, 2013a); it then gets strengthened over the Indochina Peninsula during the AMS onset, which continues for more than 1 month from the end of April/early May over the Bay of Bengal (BOB) region until the end of May/early June over North India (Wu and Zhang 1998; Wang and Lin 2002); and finally it settles over the climate mean region until autumn. The $\mathrm{SAH}$ is in fact the strongest and steadiest circulation system besides the polar vortex in the upper troposphere of the Northern Hemisphere (Mason and Anderson 1963). The geographic location of the SAH's center varies at different timescales ranging from a few days (Tao and Zhu 1964) to 
quasi-biweekly (Krishnamurti 1973; Luo and Yanai 1983, 1984; Liu et al. 2007; Peng et al. 2014) and even longer (Zhang et al. 2002). The activities of the SAH are closely linked to local weather variation and have been used as an index for short- to medium-range weather forecasts in Asia (Ye and Gao 1979).

How the gigantic SAH is formed and maintained has long been a subject of interest to meteorologists. Strong summer heating over the TP was once considered a major contributor to its formation (Flohn 1957; Yeh et al. 1957; Yanai et al. 1992), and the strong latent heat release associated with the ASM was later shown to have important impacts on its maintenance (Chen 1985; Liu et al. 2001, 2013b). Wu and Liu (2003) and Wu et al. (2009) found that the summertime circulation configuration in the subtropics is a consequence of the atmospheric response to an organized continental-scale quadruple diabatic heating (LOngwave radiation cooling, surface SEnsible heating, COndensation heating, and Double dominant heating; called LOSECOD), together with local-scale sea breeze forcing and regional-scale mountain forcing. In this regard, the huge and strong SAH is due mainly to the large longitudinal span of the Eurasian continent and the large size and high elevation of the Iranian Plateau and the TP along the subtropics.

Another spectacular phenomenon in the upper troposphere of the subtropics in summer is a remarkable warm temperature maximum. Using a 14-year dataset, $\mathrm{Li}$ and Yanai (1996) analyzed the horizontal distribution of the mean temperature in the $200-500 \mathrm{hPa}$ layer in summer and found that "a huge warm air mass is centered on South Asia with the maximum temperature $\left(\geq-22{ }^{\circ} \mathrm{C}\right)$ over the southern TP." Though there are numerous studies on the formation and variation of the $\mathrm{SAH}$, there are a lot fewer studies on the formation of this upper-troposphere-temperature-maximum (UTTM). Tamura et al. (2010) found an abrupt temperature increase in the upper troposphere southwest of the TP during the early ASM monsoon onset from late April to mid-June, and suggested that this was due to local adiabatic warming that was closely associated with the anomalous Hadley circulation. Several proposals have attributed the formation of the UTTM to various external thermal forcing. Early investigations emphasized the importance of the thermal forcing of the TP (e.g., Yeh et al. 1957; Flohn 1957; Hahn and Manabe 1975; Ye and Gao 1979). Based on ECMWF TOGA analyses on a $2.5^{\circ} \times 2.5^{\circ}$ grid from 1985 to 1992, Yanai and $\mathrm{Li}$ (1996) demonstrated that in the boreal summer months the maximum vertically integrated heat source $\left\langle Q_{1}\right\rangle$, moisture sink $\left\langle Q_{2}\right\rangle$, and minimum OLR flux are all located in a region stretching from the southern TP to the northern $\mathrm{BOB}$, indicating the importance of monsoon condensation heating in the development of the warm center.
Another proposal concerning the location of the UTTM is based on local vertical coupling: the precipitating convection over North India thermodynamically couples the upper troposphere to the air of the highest entropy subcloud layer so that the "thermal forcing of continental India is important in setting the location and amplitude of the UTTM" (Boos and Kuang 2010, 2013). However, the statistical-equilibrium theory (Emanuel 1991; Emanuel et al. 1994) links the change in the subcloud-layer entropy $\theta_{e}$ to the change in the thickness (virtual temperature) of the convective layer bounded between the free and lifted convection levels, rather than the entropy and temperature themselves. The thickness was defined from the convective cloud base to the cloud top extending through most of the troposphere, which is between 150 and $800 \mathrm{hPa}$ over North India in the observation (Fig. 2 in Boos and Kuang 2010), and is different from the UTTM layer, which is in the upper troposphere between 400 and $200 \mathrm{hPa}$. Furthermore, convective diabatic heating in the tropics is substantially balanced by adiabatic cooling as well as longwave radiation cooling (Sardeshmukh and Hoskins 1985; Rodwell and Hoskins 2001). Therefore, can the convective heating over North India locally couple the UTTM to the high subcloud entropy? If not, what is the mechanism responsible for its formation and variation? These are challenging issues in monsoon dynamics. In this study, we will investigate the general configuration of the SAH and UTTM and analyze their relation with external diabatic heating and the associated mechanism based on data diagnosis, general circulation numerical experiments and dynamic analysis. The rest of the text is organized as follows: Sect. 2 presents the latitude locations of large-scale tropical monsoon systems, including the SAH, UTTM, surface entropy, and monsoon convection. The intrinsic coherent structure among these systems is analyzed based on the geostrophic and thermal wind balances and axisymmetric monsoon dynamics. The longitude location of the UTTM in relation with the vertical gradient of diabatic heating, the so-called $\boldsymbol{T}-\boldsymbol{Q}_{\boldsymbol{Z}}\left(\boldsymbol{Q}_{z}=\partial \boldsymbol{Q} / \partial z\right)$ relation, and the associated mechanism are discussed in Sect. 3. Such a newly established $\boldsymbol{T}-\boldsymbol{Q}_{Z}$ relation is compared to the Gill's (1980) model in Sect. 4. In Sect. 5, time dependent numerical sensitivity experiments are used to verify the rendered mechanism. The implication of the results for the observed regional climate change is explored in Sect. 6. Discussion and conclusion are presented in Sect. 7.

\section{Latitude location of the UTTM}

The observational monthly datasets used in this study are derived from ERA40 datasets (Uppala et al. 2005). The summer climate equilibrium state is indicated by climate variables averaged for the June-July-August (JJA) period 
a

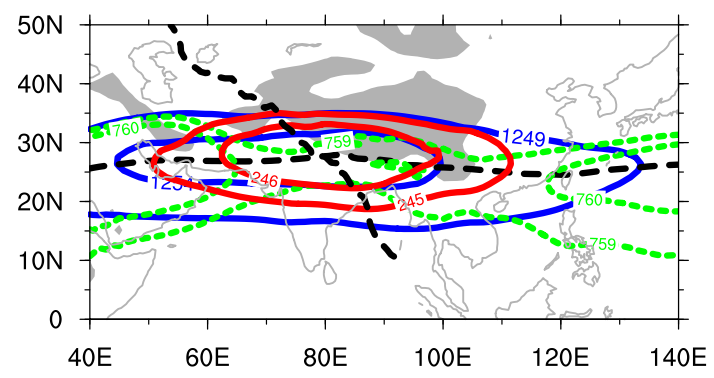

b
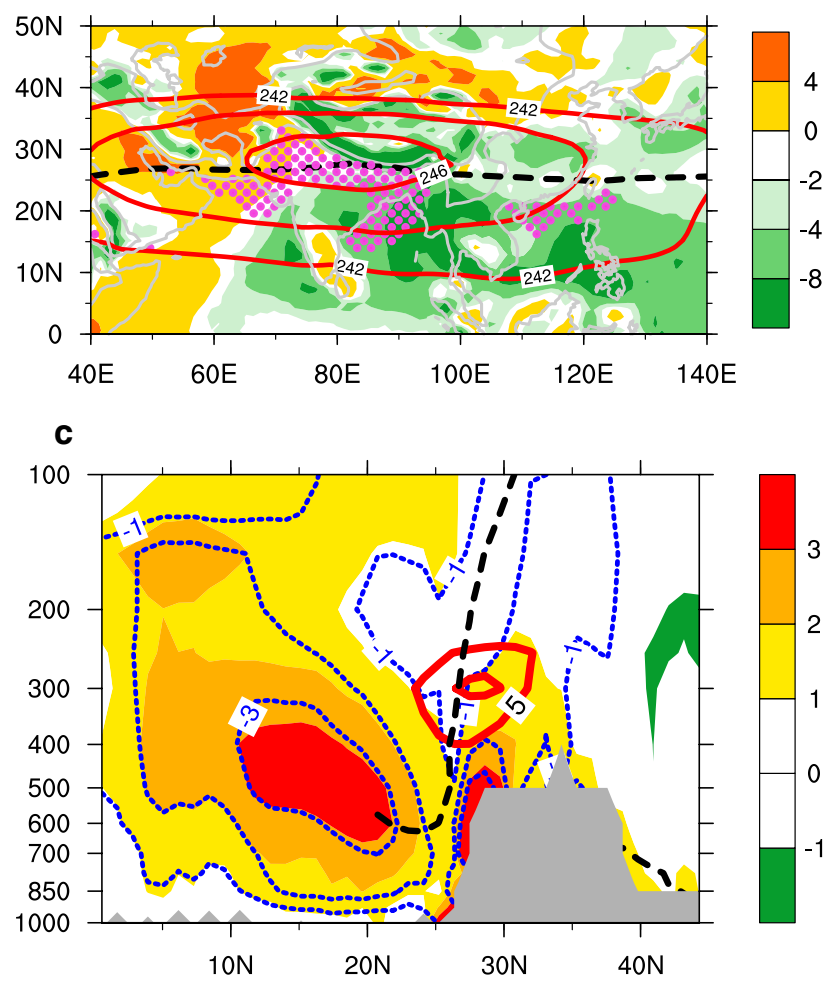

Fig. 1 The JJA mean distributions of a geopotential height (unit: dgpm) at $200 \mathrm{hPa}$ (blue solid) and $400 \mathrm{hPa}$ (green dashed), 200$400 \mathrm{hPa}$ mass-weighted mean temperature (red solid, unit: K), and zero zonal and meridional wind contours at $200 \mathrm{hPa}$ (black dashed); b $500-\mathrm{hPa}$ vertical velocity (shading, unit: $\mathrm{hPa} \mathrm{s} \mathrm{s}^{-1}$ ), 200-400 hPa mass-weighted mean temperature (red contour, unit: K), surface entropy $>356 \mathrm{~K}$ (purple stippled; unit: $\mathrm{K}$ ), and contour of $u=0$ at $300 \mathrm{hPa}$ (black dashed); and c $60^{\circ}-100^{\circ} \mathrm{E}$ mean diabatic heating $Q_{1} / c_{p}$ (shading, unit: $\mathrm{K} \mathrm{d}^{-1}$ ) and adiabatic heating (blue dotted contour, unit: $\mathrm{K} \mathrm{d}^{-1}$ ), ridgeline (black dashed line), and temperature deviation from the $\left(40^{\circ}-160^{\circ} \mathrm{E}, 0^{\circ}-50^{\circ} \mathrm{N}\right)$ area mean (red contour, interval: $5{ }^{\circ} \mathrm{C}$ )

from 1979 to 2002. For precipitation, the PREC/L data (Chen et al. 2002) are applied.

In summer in the upper troposphere over the Asian monsoon area, a zonal belt of high geopotential is located between $15^{\circ}$ and $35^{\circ} \mathrm{N}$, and its magnitude increases with height (Fig. 1a). At $400 \mathrm{hPa}$, regions higher than 760-dgpm (green) appear over the western Pacific and above Saudi
Arabia, while a weak subtropical ridge just emerges in the region to the south of the TP and north of the BOB. At $200 \mathrm{hPa}$, the unique SAH becomes prominent, with the 1,249-dgpm contour covering the entire Eurasian subtropics. The area encircled by 1,254-dgpm is seated from the Arabian Peninsula to the southeastern TP, with its ridgeline located along $26^{\circ}-28^{\circ} \mathrm{N}$ and its center shifted westward compared to the weak ridge at $400 \mathrm{hPa}$. A warm region of the $200-400 \mathrm{hPa}$ mass-weighted mean temperature is located along the latitudes between $20^{\circ}$ and $35^{\circ} \mathrm{N}$, forming the UTTM, with its elliptical center warmer than $246 \mathrm{~K}$, ranging from $60^{\circ}$ to $100^{\circ} \mathrm{E}$ above Afghanistan, Pakistan, North India, and the southwestern TP. Here we take the average temperature from 200 to $400 \mathrm{hPa}$, not $500 \mathrm{hPa}$, to obtain the upper troposphere mean temperature, because $500 \mathrm{hPa}$ is close to the surface of the TP and the temperature distribution at this level is strongly affected by the ground surface heating of the TP (Fig. 5 of Yanai et al. 1992). While the ridgeline of the SAH tilts northward slightly with increasing height, the elliptic long axis of the UTTM coincides well with the upper-layer SAH axis, in agreement with the fact that the axis of subtropical anticyclones always tilts toward warmer regions with increasing height (Wu et al. 2002).

Can the formation of this UTTM be attributed directly to the vertical coupling of the local convection with high surface entropy over North India? For this, the spatial pattern of UTTM should be in good coordination with high surface entropy and strong vertical motion. However, this is not the case in the subtropics, as demonstrated in Fig. 1b: the climate-mean maximum air ascent (green shading) is observed over the southern slope of the TP and South China in the subtropics, and over the eastern Arabian Sea (AS), the eastern BOB and western Indochina Peninsula region, and the SCS in the tropics; while the high surface entropy (purple stippling) appears mainly over the northern AS, northwestern BOB, and northern SCS in the tropical oceans, and over northern and northeastern India. It is interesting to see that over the ocean region of the AS, $\mathrm{BOB}$, and SCS, high surface entropy is located just to the north of strong ascent (rainfall), in good agreement with the axisymmetric theory (Prive and Plumb 2007a). However, over the northern Indian subcontinent, high surface entropy is accompanied by descent (orange shading) over the west, but ascent over the east, with the high surface entropy appearing between the two strong ascents located respectively to its north and south, presenting a surface circulation-driven east-west asymmetry of the monsoon by suppressing moist convection to the west, while encouraging rainfall in the east (Xie and Saiki 1999; Wu et al. 2009). Within the 246 K UTTM contour, while the northeastern part is characterized by strong ascent and lower entropy, its southwestern portion features descent and high entropy. In 

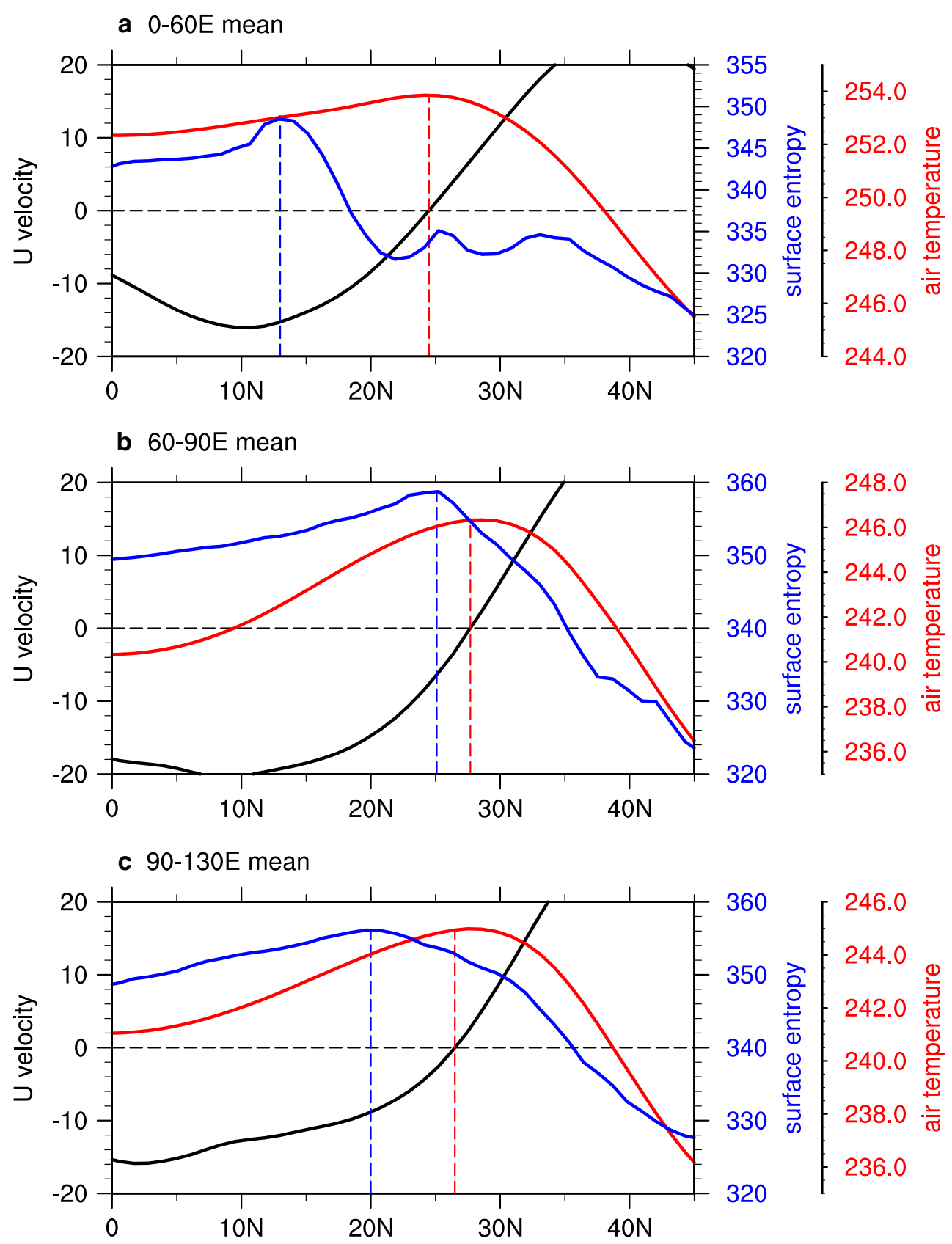

Fig. 2 ERA40 July-mean profiles of surface $\boldsymbol{\theta}_{\text {se }}$ (K, blue), 200-400 hPa mass weighted mean air temperature (K, red), and $200 \mathrm{hPa}$ zonal velocity $u\left(\mathrm{~m} \mathrm{~s}^{-1}\right.$, black) for (a) $0^{\circ}-60^{\circ} \mathrm{E}$ mean; $\mathbf{b} 60^{\circ}-90^{\circ} \mathrm{E}$ mean; and $\mathbf{c} 90^{\circ}-130^{\circ} \mathrm{E}$ mean. The black dashed line indicates $u=0$

the existence of such a highly asymmetric geometry over North India and the southwestern TP, the limitation of the axisymmetric theory is evident, as was discussed by Prive and Plumb (2007b).

To illustrate the general features more clearly, a latitudepressure cross section of the diabatic heating and adiabatic cooling, averaged over the longitudinal span of the UTTM $\left(60^{\circ}-100^{\circ} \mathrm{E}\right)$, is calculated and presented in Fig. 1c. The main diabatic heating $Q$ [shading, calculated from (10)] is over the tropics around $10^{\circ}-20^{\circ} \mathrm{N}$ and over the southern slope of the TP, corresponding respectively to the southern and northern branches of the South Asian monsoon (SAM; Wu et al. 2012a). These two heating maxima are basically compensated for by local adiabatic cooling [dotted curve, the $\omega$ term in (10)] associated with local air ascent, as was demonstrated by Rodwell and Hoskins 2001). On the other hand, the UTTM is seated in a region just between the two maximum heating centers, and the vertical motion is weak in this region.

Shown in Fig. 2 is the allocation of the $200-400 \mathrm{hPa}$ mass weighted air temperature (red), $200 \mathrm{hPa}$ zonal 
velocity (black) and surface $\boldsymbol{\theta}_{\text {se }}$ (blue) in different sectors in South Asia. It reveals the following common features in all sectors: the maximum surface entropy is associated with easterly shear in the upper troposphere, the maximum surface entropy is located to the south of the UTTM, and the UTTM is seated by the ridge line of subtropical anticyclone where $u$ vanishes. The overlapping of the UTTM and the ridgeline is subject to the following geostrophic balance, hydrostatic balance, and thermal wind relation:

$f u=-\partial \phi / \partial y$

$\partial \phi / \partial \ln p=-R T$

$\frac{\partial u}{\partial \ln p}=\frac{R}{f}\left(\frac{\partial T}{\partial y}\right)$

where $f$ is the Coriolis parameter, $u$ is zonal wind, $\phi$ is geopotential height, $y$ is the meridional coordinate, and $p, T$, and $R$ denote pressure, temperature, and the gas constant for dry air, respectively. Then higher geopotential along the SAH in the subtropics implies the occurrence of a westerly to its north and an easterly to its south, with vanishing zonal wind along its axis (1). The higher geopotential along the ridgeline also implies a thicker layer beneath corresponding to a warmer layer below (2). On the northern side of the SAH the increasing westerly flow with height corresponds to a warmer region situated to its south, whereas on the southern side of the $\mathrm{SAH}$, the increasing easterly flow with height corresponds to a warmer region situated to its north (3). In other words, the UTTM must be located along with the SAH in the upper troposphere. As demonstrated in Fig. 1a, the area of the 200-400 hPa mass-weighted temperature warmer than $245 \mathrm{~K}$ is elliptical and spans from $50^{\circ} \mathrm{E}$ to $110^{\circ} \mathrm{E}$, with its long axis coincident with the ridgeline of the subtropical anticyclone at $200 \mathrm{hPa}$.

Why should the SAH and the UTTM be located in subtropics? How the high surface entropy, the SAH and the UTTM are allocated in such a manner as shown in Fig. 2? A series of study (Schneider and Lindzen 1977; Schneider 1977, 1987; Held and Hou 1980) on the dynamics of the Hadley circulation demonstrated that in response to an axisymmetric diabatic heating, the atmospheric circulation adopts two distinct regimes: the thermal equilibrium (TE) regime in extra-tropics and the angular momentum conservation (AMC) regime in the tropics. In the TE regime the planetary vorticity is large and the Rossby radius of deformation is small, a weak forcing cannot generate meridional circulation. Whereas in the AMC regime the planetary vorticity is small and the Rossby radius of deformation is large, a relatively weak forcing may overcome the in situ planetary vorticity and produce a meridional circulation. Plumb and Hou (1992) further studied the axisymmetric atmospheric response to an off-equator external forcing centered at $25^{\circ} \mathrm{N}$ and identified the regime transition from the TE type to the AMC type. They found that for a stronger forcing the relative vorticity becomes significant and the absolute vorticity may vanish, then the atmospheric response takes the AMC form, forming a thermally forced tropical monsoonal flow. Corresponding to this monsoonal meridional circulation with a cross-equatorial southerly in the lower troposphere and a reversed northerly in the upper troposphere, a vertical easterly shear presents in tropics. Such a background is in favor of the development of large-scale ascent since absolute vorticity advection increases with height (w $\propto \partial[-\vec{V} \cdot \nabla(f+\zeta)] / \partial \mathrm{z})$. Consequently convection can develop where the surface entropy is high. The cumulus friction of the tropical convection in return can further strengthen the easterly shear with height in the upper troposphere (Schneider and Lindzen 1976, 1977). Furthermore, the easterly in the upper troposphere implies a temperature/ geopotential height increase with increasing latitude. On the contrary in extra-tropics, the temperature is in local TE and decreases polewards together with decreasing geopotential height. Consequently, a horizontal temperature/geopotential-height gradient reversal appears in the subtropics where the UTTM and SAH are located, just to the north of the surface high entropy and tropical convection.

\section{Longitude location of the UTTM and vertical gradient of diabatic heating}

In extra-tropics the zonal distribution of temperature is connected with the vertical shear of meridional wind $v$, subject to the following thermal wind relation

$\frac{\partial v}{\partial \ln p}=\frac{R}{f}\left(\frac{\partial T}{\partial x}\right)$

Since the vertical shear of meridional wind from 400 to $200 \mathrm{hPa}$ is negative to the east of the $\mathrm{SAH}$ center and positive to its west, according to (4) the maximum temperature in the 400-200 hPa layer should be located near the $\mathrm{SAH}$ center, as shown in Fig. 1a. The above analyses thus show that the center of the UTTM is coincident with the center of the SAH aloft. In other words, the SAH is a warm entity in nature. Now the problem becomes where in the subtropics the SAH and UTTM should be located.

Since the latitude location of the UTTM coincides with the SAH, and since in the subtropics $u \approx 0$ and $\partial \zeta / \partial y \approx 0$, the relative vorticity advection is negligible there. At a steady state and in a frictionless atmosphere the vorticity generation in the subtropics due to diabatic heating should be balanced by planetary vorticity advection (Liu et al. 2001):

$$
\begin{array}{r}
\beta v \approx(f+\zeta) \theta_{z}^{-1}(\partial Q / \partial z)-g\left(f T \theta_{z}\right)^{-1}(\partial T / \partial x)(\partial Q / \partial x) \\
-g\left(f T \theta_{z}\right)^{-1}(\partial T / \partial y)(\partial Q / \partial y), \theta_{z} \neq 0, \vec{V} \cdot \nabla \zeta \rightarrow 0
\end{array}
$$


where $\beta=d f / d y, \quad \theta_{z}=\partial \theta / \partial z, \zeta$ is relative vorticity, $\theta$ is potential temperature, $g$ is acceleration of gravity, and $Q$ is the diabatic heating. Assuming the following variable scales in the upper troposphere (Wu et al. 1999):

$$
\begin{aligned}
\theta_{z} & \sim 10^{-2} \mathrm{~K} \mathrm{~m}^{-1}, \Delta T \sim 10 \mathrm{~K},(\Delta x, \Delta y) \sim 10^{6} \\
\mathrm{~m}, \Delta z & \sim 10^{3} \mathrm{~m}, Q \sim 10^{-5} \mathrm{~K} \mathrm{~s}^{-1} .
\end{aligned}
$$

Then the orders of magnitude for the three terms on the right-hand side of (5) are, respectively, $10^{-10} \mathrm{~s}^{-2}$, $10^{-11} \mathrm{~s}^{-2}$, and $10^{-11} \mathrm{~s}^{-2}$. This implies that the vorticity generation induced by horizontally inhomogeneous heating is at least one order of magnitude smaller than that due to the vertical heating gradient. Thus, the relation between meridional wind and the vertical gradient of diabatic heating $Q$ can be well expressed as the following Sverdrup balance (Liu et al. 2001):

$\beta v \approx(f+\zeta) \theta_{z}^{-1}(\partial Q / \partial z), \quad \theta_{z} \neq 0, \vec{V} \cdot \nabla \zeta \rightarrow 0$.

where

$z=-H \cdot \ln p$,

in which $H$ is the scale height of the atmosphere. Taking the derivative of (4) with respect to $x$ and substituting (6) into the resultant equation leads to:

$\left\{\begin{array}{l}\frac{\partial^{2} T}{\partial x^{2}} \approx \gamma \frac{\partial}{\partial x}\left(\frac{\partial^{2} Q}{\partial z^{2}}\right), \quad \vec{V} \cdot \nabla \zeta \rightarrow 0 \\ \gamma=f(f+\zeta) H /\left(R \beta \theta_{z}\right), \quad \theta_{z} \neq 0 .\end{array}\right.$

Since the domain under consideration is in the upper troposphere in the subtropics, in deriving (7) the local vertical variation of $\left[(f+\zeta) \theta_{z}^{-1}\right] \approx\left(f \theta_{z}^{-1}\right)$ is neglected. Thus the parameter $\gamma$ can be considered a constant along the $x$ axis. Assume normal mode distributions for both diabatic heating $Q$ and deviation (from zonal mean) temperature $T$ :

$\left\{\begin{array}{l}Q=Q(x) \cos \left(\frac{\pi z}{H_{Q}}\right) \\ T=T(x) \cos \left(\frac{\pi z}{H_{Q}}\right) \\ T(x)=T_{0} \cos \left(\frac{\pi x}{L}\right) .\end{array}\right.$

Here, $H_{Q}$ is the characteristic height of diabatic heating $Q, T_{0}$ is the amplitude of temperature, and $L$ is the characteristic horizontal scale of the temperature center. Substituting (8) into (7) leads to the following $\boldsymbol{T}-\boldsymbol{Q}_{Z}$ relation between the temperature and the vertical gradient of diabatic heating $Q$ :

$\left\{\begin{array}{l}T(x) \approx \gamma L^{2} H_{Q}^{-2} \partial Q(x) / \partial x=\lambda \partial Q(x) / \partial x, \quad \overrightarrow{\mathrm{V}} \cdot \nabla \zeta \rightarrow 0 \\ \lambda=\gamma L^{2} H_{Q}^{-2} .\end{array}\right.$
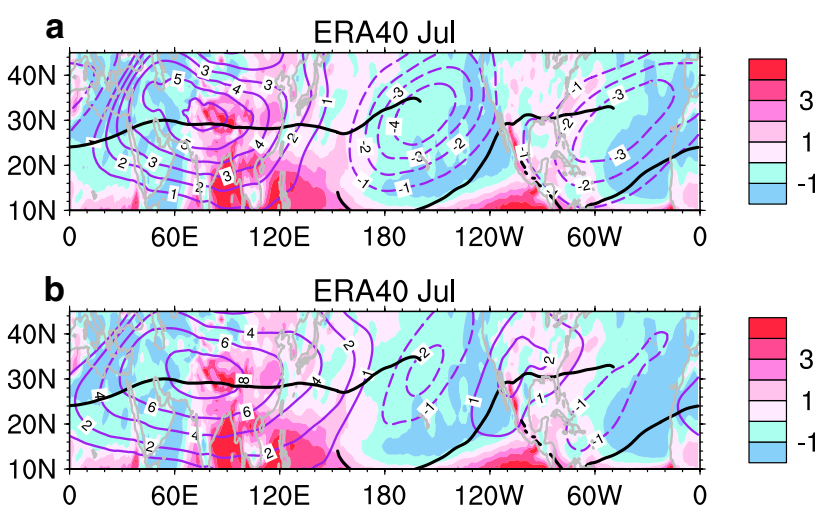

Fig. 3 1979-1998 July-mean 200-400 hPa averaged air temperature deviation ( $\mathrm{K}$, blue contour) from the zonal mean (a) and from the $180^{\circ}-360^{\circ} \mathrm{E}$ mean $(\mathbf{b})$, and diabatic heating $\left(\mathrm{K} \mathrm{d}^{-1}\right.$, shading $)$. Heavy black curve indicates where $u=0$, and $\partial u / \partial y>0$

Solution (9) indicates that in the subtropics, the maximum temperature is on the west/east of diabatic heating/ cooling $Q$ for a quarter of a wavelength, and the minimum temperature is on the west/east of diabatic cooling/ heating $\boldsymbol{Q}$ for a quarter of a wavelength. The stronger the heating and the larger of the longitudinal scale of the temperature, the stronger the deviated temperature center. Figure 3 shows the climate mean July-distributions of the 200-400 $\mathrm{hPa}$ averaged air temperature $\boldsymbol{T}$ and diabatic heating $Q$ in the northern hemisphere. The calculation of $Q$ in this study is from the expression of apparent heat source (Yanai et al. 1973) as follows:

$Q=\frac{Q_{1}}{c_{p}}=\left(\frac{p}{p_{0}}\right)^{\kappa}\left(\frac{\partial \theta}{\partial t}+\vec{V} \cdot \nabla \theta+\omega \frac{\partial \theta}{\partial p}\right)$.

where $Q_{1}$ is the apparent heat source, $c_{p}$ is the specific heat of air at constant pressure, $p_{0}$ is $1,000 \mathrm{hPa}, k=R / c_{p}$, and $\omega$ is vertical velocity in the $p$-coordinate. Figure 3 shows that two warm centers are located over the Eurasian (Fig. 3a) and North American (Fig. 3b) continents, with their long axes being coincident with the local ridgelines of the subtropical anticyclone. Diabatic heating and cooling are respectively located to their east and west, and the much stronger warm center over Eurasia than over North America is accompanied with much stronger heating and larger longitude span, in agreement with the $\boldsymbol{T}-\boldsymbol{Q}_{Z}$ relation (9) just developed. Two cold centers are located over Northern Pacific and Northern Atlantic (Fig. 3a). Due to the existence of the upper tropospheric trough over ocean in summer, the ridgeline is broken over the eastern ocean. Even so, the cold trough over ocean is accompanied with heating in its west and long wave radiation cooling in its east, closely subject to the $\boldsymbol{T}-\boldsymbol{Q}_{Z}$ relation.

Let us focus on the UTTM. Figure $4 \mathrm{a}$ shows the distribution of diabatic heating $Q$ for the upper troposphere 

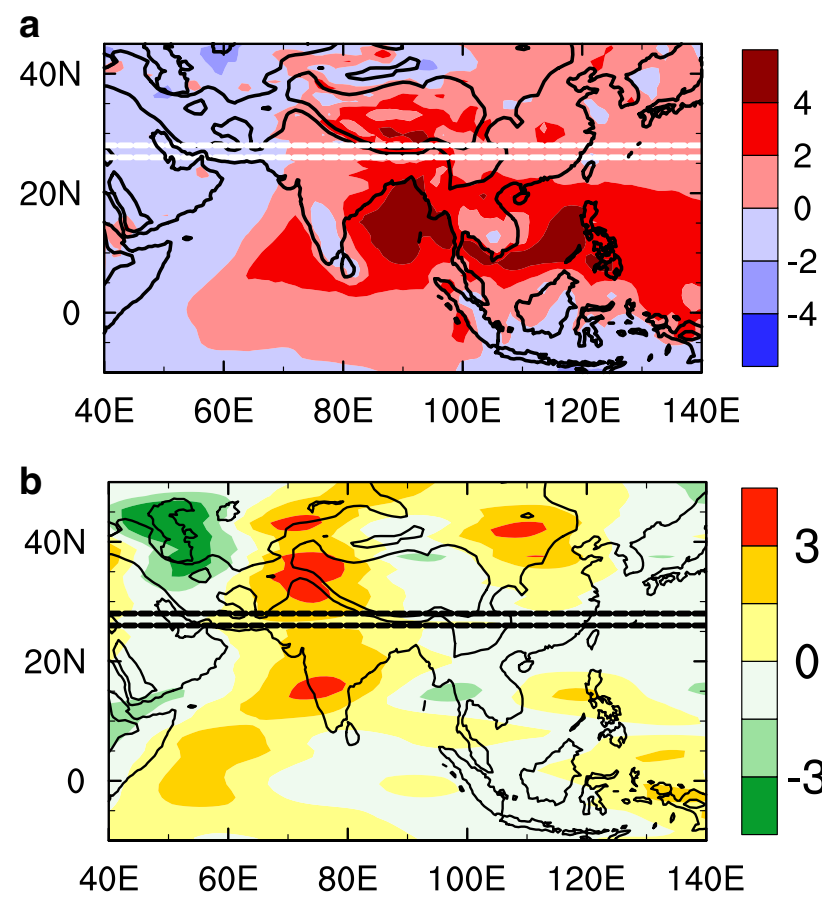

c

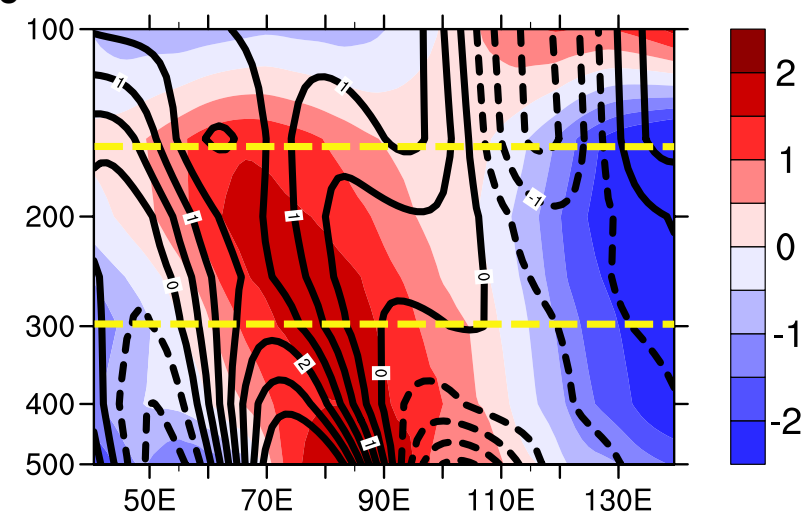

d

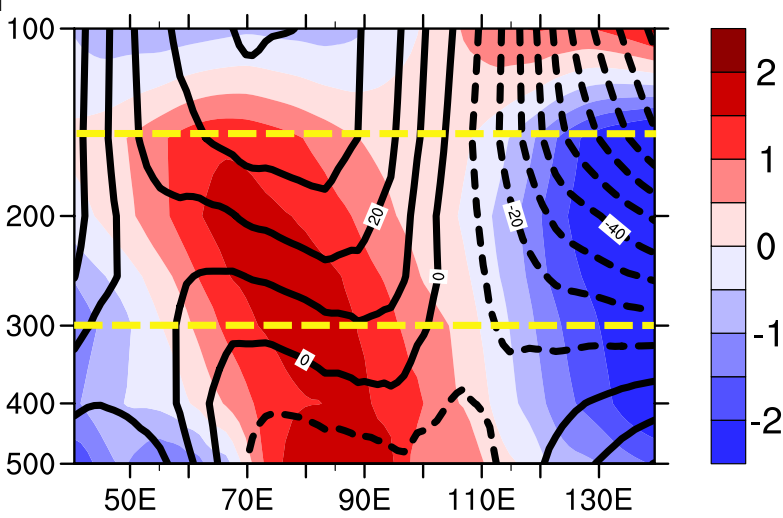

Fig. 4 The JJA mean distributions of the 200-400 hPa mass-weighted mean a diabatic heating rate and $\mathbf{b}$ the calculated temperature $\lambda \partial Q(x) / \partial x$; and the $26^{\circ}-28^{\circ} \mathrm{N}$ mean cross sections of the deviations from their $40^{\circ}-140^{\circ} \mathrm{E}$ means of $\mathbf{c}$ calculated temperature $\lambda \partial Q(x) / \partial x$ (contour) and temperature in reanalysis (shading) and $\mathbf{d}$ temperature (shading) and geopotential height (contour) in reanalysis. Units are $\mathrm{K} \mathrm{d}^{-1}$ in (a), $\mathrm{K}$ for temperature in (b)-(d), and gpm for geopotential height in (d) averaged between 400 and $200 \mathrm{hPa}$. Along the latitude belt of $26^{\circ}-28^{\circ} \mathrm{N}$ where the ridgeline of $\mathrm{SAH}$ is located, the positive/negative heating is located to the east/west of $70^{\circ} \mathrm{E}$, with the heating maximum appearing near $90^{\circ} \mathrm{E}$. The heating in the east is due to monsoon condensation, and the cooling in the west is longwave radiation cooling, in good agreement with the summertime LOSECOD heating pattern in the subtropics ( $\mathrm{Wu}$ et al. 2009). The corresponding temperature distribution along $26^{\circ}-28^{\circ} \mathrm{N}$ calculated based on (9) demonstrates a positive phase to the east of the cooling and west of the heating maximum, spanning between $60^{\circ}$ and $90^{\circ} \mathrm{E}$ (Fig. 4b), in good correspondence with the observed $246 \mathrm{~K}$ contour of the UTTM as shown in Fig. 1a. The vertical-longitude cross section of the temperature distribution averaged along the latitude belt of $26^{\circ}-28^{\circ} \mathrm{N}$ as presented in Fig. $4 \mathrm{c}$ demonstrates that despite the unevenness of the heating near $90^{\circ} \mathrm{E}$, the calculated temperature (contour) and the temperature retrieved from the ERA40 reanalysis (shading) are generally in phase and both exhibit westward tilting with increasing height. In the upper layer between 300 and $120 \mathrm{hPa}$, the UTTM denoted by the positive temperature deviation is located between $50^{\circ}$ and $110^{\circ} \mathrm{E}$ in both the calculation and reanalysis. The calculated temperature anomalous center is $1.5-2.0^{\circ} \mathrm{C}$, which is also close to the reanalysis $\left(>1.5^{\circ} \mathrm{C}\right)$.

There is a phase difference between the calculated temperature and the temperature obtained from reanalysis in the layer below $300 \mathrm{hPa}$. Particularly at $500 \mathrm{hPa}$, the "observed" warm maximum is over the TP centered at $90^{\circ} \mathrm{E}$, whereas the calculated warm maximum is located to its west, centered near $75^{\circ} \mathrm{E}$. This may be due to the strong impact of surface sensible heating, since diffusive surface heating can directly warm up the in situ atmosphere (Luo and Yanai 1984) so that $Q$ and $T$ are in phase there, indicating the limitation of the $\boldsymbol{T}-\boldsymbol{Q}_{\boldsymbol{Z}}$ relation in the lower troposphere. Such phase shifting decreases with increasing height. At $300 \mathrm{hPa}$ the calculated UTTM center is located at $70^{\circ} \mathrm{E}$, which is shifted westward by about $10^{\circ}$ of longitude compared to the reanalysis; at levels above $200 \mathrm{hPa}$ it agrees well with the reanalysis. The distributions in the reanalysis of geopotential height and temperature deviations from their means at $40^{\circ}-140^{\circ} \mathrm{E}$ (Fig. 4d) demonstrate that in coordination with the warm center, the deviation of geopotential height is positive in the upper layers and negative in the lower layers, indicating increased air column thickness. While the warm center presents westward tilting, the SAH axis also tilts westward with height. The SAH becomes well defined above $350 \mathrm{hPa}$, just above the warm center.

The primary cause of cooling being located to the west of heating over Eurasia is due to the continentalscale thermal forcing along the subtropics ( $\mathrm{Wu}$ et al. 


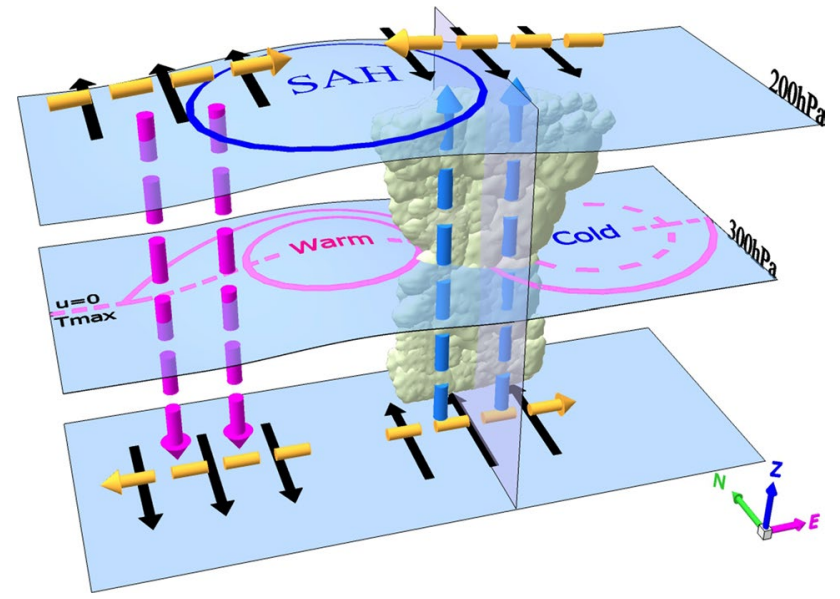

Fig. 5 Schematic diagram of the $\boldsymbol{T}-\boldsymbol{Q}_{Z}$ mechanism contributing to the longitudinal location of the UTTM: Strong monsoon convective latent heating along the subtropics (blue upward arrow) results in the local development of a vertical northerly shear (black arrow), and induces an eastward decreasing temperature gradient over the heated layer in the upper troposphere, forming the UTTM and the aloft SAH to the west of the heating. The vertical southerly shear over the western Eurasian subtropics, which is due to strong surface sensible heating and longwave radiation cooling (red downward arrow) in the upper troposphere, contributes to the occurrence of the UTTM and SAH on the eastern end of the cooling. The induced Coriolis force $(f v$, orange arrow) is in geostrophic balance with the pressure gradient force. Refer to text for details

2009): in summer the atmospheric heating source is over continent while heating sink is over ocean. Along the subtropics, a heating generates air ascent (decent) in the east (west); whereas a cooling generates air descent (ascent) in the east (west). Consequently, in the upper troposphere the thermal forcing in summer generates air ascent to the east (west) and descent to the west (east) over continent (ocean), corresponding to the configuration with condensation heating being located to the east of long wave cooling over continent but to its west over ocean as demonstrated in Fig. 3. It is worthwhile to mention that, while the convective heating on the east of the UTTM is strong and uneven, the cooling on its west is weak and relatively uniform (Fig. 4a). This may due to the fact that, part of the longwave radiation comes from the response to the monsoonal convective heating to its east (Rodwell and Hoskins 1996, 2001) and imply that the monsoon latent heating in the east is more active in forcing the UTTM.

The underpinning mechanism can be understood by the schematic diagram shown in Fig. 5. Along the subtropical latitude belt where the SAH is seated, huge condensation heating occurs mainly over and to the east of the southern TP (blue upward arrow), with its maximum located in the middle troposphere close to $400 \mathrm{hPa}$. Positive/negative vorticity is thus generated in the lower/upper troposphere below/above the heating maximum [right-hand side of (6)]. Because the relative vorticity advection in subtropics is weak, negative/positive planetary vorticity advection in the lower/upper troposphere is required to maintain the atmosphere at a steady state [left-hand side of (6)], resulting in the local development of a southerly/northerly (black arrow) in the lower/upper troposphere (Wu et al. 1999; Liu et al. 1999, 2001). Under the thermal wind constrain (4), such a vertical northerly shear over the monsoon convection region should be accompanied with a warm center on its west and a cold center on its east. Therefore the dynamics of the $\boldsymbol{T}-\boldsymbol{Q}_{Z}$ relation can be interpreted as follows: In summer along the subtropics where the relative vorticity advection is weak, the UTTM should be generated to the west of the strong Asian monsoon convection so that the vertical northerly shear of the meridional wind induced by the convective heating is balanced by the zonal temperature gradient, and the SAH is produced aloft. Consequently, the Coriolis force $(f v<0$, orange arrow at $200 \mathrm{hPa})$ associated with the northerly flow in the upper troposphere above the convective heating is balanced by the eastward pressure gradient force $(-\partial \phi / \partial x>0)$, and a new geostrophic and hydrostatic equilibrium state in the subtropics can be achieved.

A similar argument can be applied to the contributions of cooling (purple downward arrow) in the west to the UTTM. Over the subtropical western continent in summer, atmospheric heating is characterized as strong surface sensible heating in the lower troposphere but longwave radiation cooling in the upper troposphere (Wu and Liu 2003; Wu et al. 2009). Because surface sensible heating and longwave radiation cooling both decrease with height, according to (6) vertical southerly shear is generated in the west of the UTTM. Following the thermal wind constraint (4), the vertically averaged air temperature in the east of the southerly shear region should be warmer than that in the west, and the UTTM should develop in the eastern end of the cooling, as depicted in Fig. 5.

\section{Comparison of the $T-Q_{Z}$ model with the Gill's model}

It should be pointed out that either the Gill's model or the $\boldsymbol{T}-\boldsymbol{Q}_{Z}$ model does not apply in middle and high latitudes. This is because in higher latitudes the Burger number $\left(B=N^{2} H_{Q}^{2} / f^{2} L^{2}\right.$, in which $N=\left((g / \theta) \theta_{z}\right)^{1 / 2}$ is the Brunt-Vaisala frequency, $H_{Q}$ is a characteristic height of heating, and $L=(u / \beta)^{1 / 2}$ is the wave length of stationary Rossby wave) is small $\left(\mathrm{B} \approx 10^{-1}\right.$ ) (Hoskins 1987), and the thermodynamic equation takes an advection-limit approximation (Smagorinsky 1953). Warm temperature is thus formed downstream of a heating center. Whereas in subtropics and tropics the Burger number is much larger $\left(\mathrm{B} \approx 10^{0}-10^{1}\right)$, where 
temperature advection becomes secondary and the relation between heating and temperature distribution is more complicated. In the following we will make comparisons between the Gill's model and the $\boldsymbol{T}-\boldsymbol{Q}_{Z}$ model just developed.

\subsection{Consistency of the Gill's model with the potential vorticity theory}

The Gill's model (Gill 1980) is a shallow-water equation model in the tropics and at the surface, which uses the equatorial beta-plane approximation and takes the following non-dimensional form:

$\varepsilon u-\frac{y}{2} v=-\frac{\partial p}{\partial x}$

$\varepsilon v+\frac{y}{2} u=-\frac{\partial p}{\partial y}$

$\varepsilon p+\frac{\partial u}{\partial x}+\frac{\partial v}{\partial y}=-Q$

In this model, $(x, y)$ are non-dimensional distance with $x$ eastwards and $y$ measured northwards from the equator. The parameter $\varepsilon$ represents Rayleigh friction as well as Newtonian cooling, and $p$ is surface pressure. $\boldsymbol{Q}$ is defined as a "heating rate". The Gill's model has been successfully used in interpreting the tropical dynamics particularly in the lower troposphere. Can this model be directly used to study the subtropical dynamics in the upper troposphere? From (11) the following steady-state vorticity equation can be reached:

$\frac{1}{2} v=\frac{y}{2} Q+\frac{y}{2} \varepsilon p-\varepsilon \zeta$

Comparing (12) with (6), one can find that $Q$ in (11.3) is actually presenting a vorticity forcing source rather than a heating itself. Defining $Q$ in (11.3) as a "heating rate" will lead to inconsistency with the potential vorticity $(P V)$ dynamics if the vertical gradient of diabatic heating is of opposite sign with the heating itself. This is because, following the $P V$ theorem (Ertel 1942; Hoskins et al. 1985; Wu and Liu 2000), a vertical vorticity source is proportional to the vertical heating gradient $\partial \boldsymbol{Q} / \partial z$. For a heating that is increasing with height $(\partial \boldsymbol{Q} / \partial z>0)$, the static stability of the heated layer is increased and positive vorticity is generated. Thus the vorticity forcing possesses the same sign as the heating, and southerly is induced in the heating region with low pressure located in the west of the heating following either (12) or (6). However, if the heating is decreasing with height $(\partial \boldsymbol{Q} / \partial z<0)$, a negative vorticity is produced in the heating region because the static stability of the heated layer is decreased, and a northerly is required to transport positive planetary vorticity for maintaining a steady state according to the $P V$ relation (6). High pressure (warm temperature) thus develops in the west of the heating. Whereas in the Gill's model (11), the prescribed heating still produces southerly (12) with low pressure (cold temperature) developing in its west, which is opposite to the observation as shown in Fig. 3 and results in inconsistency with the $P V$ theory. Similar argument can be applied to the case when a cooling source $(Q<0)$ is decreasing with height $(\partial \boldsymbol{Q} / \partial z>0)$. Since both the vertically decreasing convective heating and vertically decreasing longwave radiation cooling occur in the upper troposphere, it means that defining $\boldsymbol{Q}$ as a heating rate may hamper the application of the Gill's model to the upper troposphere.

\subsection{Applicability of the Gill's model in the upper troposphere}

The above inconsistency can be overcome if the original "heating rate $\boldsymbol{Q}$ " in the Gill's model is replaced by a vorticity forcing source that is proportional to the vertical heating gradient $\partial \boldsymbol{Q} / \partial z$, and the modified Gill's model becomes equivalent to the following form:

$$
\begin{aligned}
& \varepsilon u-\frac{y}{2} v=-\frac{\partial p}{\partial x} \\
& \varepsilon v+\frac{y}{2} u=-\frac{\partial p}{\partial y} \\
& \frac{1}{2} v=\frac{y}{2} \frac{\partial Q}{\partial z}+\frac{y}{2} \varepsilon p-\varepsilon \zeta
\end{aligned}
$$

In which (13.3) is the corresponding modified vorticity equation, which then becomes consistent with the $P V$ dynamics (6). For a prescribed forcing $\partial \boldsymbol{Q} / \partial z$, there are three unknowns, i.e., $u, v$, and $p$. In such case, prescribing any inadequate solution for any unknown may lead to an incompatible set of equation. For instance, one cannot set $u=0$ then employ this system to study the subtropical anticyclone system along the ridgeline because by doing so the equation set becomes a set of three equations with two unknowns. In other words, caution is needed when employing the original Gill's model to study the subtropical dynamics.

Another limitation in applying Gill's model in the upper troposphere is the existence of dissipation. In the frictionless $\boldsymbol{T}-\boldsymbol{Q}_{Z}$ model only meridional wind is generated over the heating (cooling) region in the subtropics, and circulation and temperature centers are produced right along the same latitude of the heating region. Due to the existence of friction in the Gill's model, southwesterly (northeasterly) is generated over the heating (cooling) 
region, and cyclone (anticyclone) circulation is produced to the northwest of heating (cooling) source region. The strong friction and the extra Newtonian cooling impact $(y \varepsilon p / 2)$ may generate too much positive vorticity (13.3) and too strong wind (13.1 and 13.3) in higher latitudes, and causing bias of the circulation response in higher latitude in the upper troposphere.

It is interesting to demonstrate that if the Rayleigh friction and Newtonian cooling are further removed from the modified Gill's model (13), the system becomes:

$-\frac{y}{2} v=-\frac{\partial p}{\partial x}$

$\frac{y}{2} u=-\frac{\partial p}{\partial y}$

$\frac{1}{2} v=\frac{y}{2} \frac{\partial Q}{\partial z}$

Such a non-dissipative system is thus equivalent to our hydrostatic and Sverdrup vorticity balanced system [formula (4) and (6)]. It can now be employed to investigate the subtropical dynamics even for a prescribed solution of $\boldsymbol{u}=0$. In such circumstances, the solution becomes

$u=-\frac{2}{y} \frac{\partial p}{\partial y}=0$

$v=y \frac{\partial Q}{\partial z}$

$p(x)=p\left(x_{0}\right)+\int \frac{y^{2}}{2} \frac{\partial Q}{\partial z} \mathrm{~d} x$

In the upper troposphere, the deep convective heating and longwave radiation cooling both decrease with increasing height. Solution (15) then indicates the development of northerly over a heating region and southerly over a cooling region, with high pressure (also warm temperature) being located between heating in the east and cooling in the west and low pressure (also cold temperature) being located between heating in the west and cooling in the east. These conclusions are in agreement with the solution (9) we just obtained based on the $P V$ framework.

The above discussions demonstrate that for the original Gill's surface model to be consistent with the potential vorticity dynamics and applicable in the upper troposphere, two modifications are needed. One is to replace the "heating rate" $(\boldsymbol{Q})$ in the original model version of the continuity equation by a vorticity forcing that is proportional to the vertical heating gradient $(\partial Q / \partial \mathrm{z})$; and another is to remove or substantially reduce the momentum friction and Newtonian cooling.

\section{Numerical experiments}

To verify the proposed $\boldsymbol{T}-\boldsymbol{Q}_{Z}$ mechanism which is developed for a steady state atmosphere and see whether the change in the UTTM over North India can be attributed to the change in the monsoon latent heating to its east, a set of numerical experiments is designed using the time-dependent Spectral Atmospheric Model developed at IAP/LASG (SAMIL; Wu et al. 2003; Bao et al. 2010), which can reasonably simulate the East Asian monsoon (Wu et al. 2012a; Bao et al. 2013). A 10-year integration of the SAMIL is defined as the control run CON. Because the ridgeline of the $\mathrm{SAH}$ in $\mathrm{CON}$ is located around $30^{\circ} \mathrm{N}$, which deviates from its counterpart in reanalysis (Fig. 1a) by about 3-4 degrees northward, a box over the Asian monsoon region bounded by $90^{\circ}-120^{\circ} \mathrm{E}$ and $28^{\circ}-32^{\circ} \mathrm{N}$ along the modeled SAH axis is selected as the forcing source region $\mathrm{S}$ for designing a sensitivity experiment SEN, as indicated in Fig. 6a. In this SEN experiment every setting is the same as in the $\mathrm{CON}$ run except that in the thermodynamic equation, an extra convective heating, which is characterized by a cosine vertical heating profile with a maximum of $3{ }^{\circ} \mathrm{C}$ per day located at $500 \mathrm{hPa}$, is added in the box region during JJA. Both the CON and SEN experiments are integrated for 10 years, and the results from the last 5 years are extracted for the comparison studies.

This imposed convective heating results in increased rainfall of more than $1 \mathrm{~mm}$ per day in the source region and decreased rainfall of more than $1 \mathrm{~mm}$ per day to the west of the forcing (Fig. 6a). Consequently, the local northerly at $200 \mathrm{hPa}$ is enhanced, contributing to the intensification of the SAH to the west. This is similar to the result obtained by Schneider (1987), who used a steady, nonlinear, inviscid, shallow-water equation model to study the low-latitude upper tropospheric circulation response to zonal asymmetric forcing and found that the upper tropospheric divergent northerly is generated over the forcing region (his Fig. 1b). The time means of UTTM in July in the two experiments are presented in Fig. 6b. It shows that due to the enhanced heating in the box region, the areas encircled by the 244 , 245 , and $246 \mathrm{~K}$ isotherms in the SEN experiment (dashed contours) are all enlarged compared to their counterparts in the CON run (solid contours). The $28^{\circ}-32^{\circ} \mathrm{N}$ averaged longitude-height cross-section (Fig. 6c) demonstrates the existence of an anticlockwise secondary circulation with strong air ascent over the source region, where intensified heating is imposed and air descends to the west of the heating region, which presents a Rossby wave response to the forcing as revealed in Rodwell and Hoskins (2001). Below $300 \mathrm{hPa}$, the air gets warmer by more than $0.6^{\circ} \mathrm{C}$ between 500 and $300 \mathrm{hPa}$ to the east of $90^{\circ} \mathrm{E}$ due to direct convective heating. In the upper troposphere air warming of more than $0.4{ }^{\circ} \mathrm{C}$ appears to the west of $90^{\circ} \mathrm{E}$. All these results 


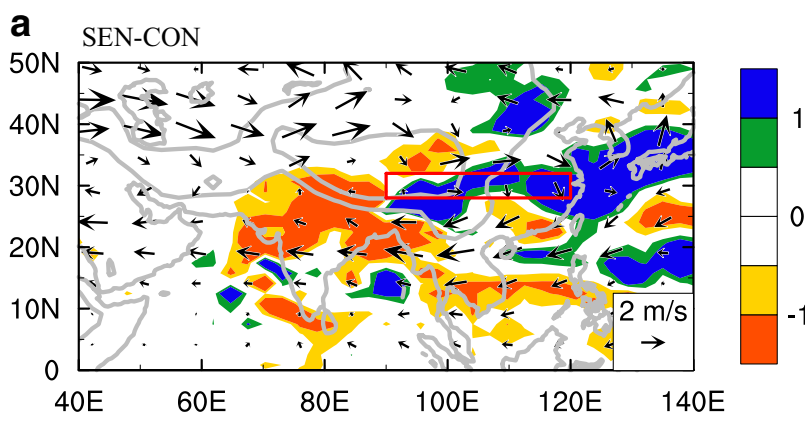

b

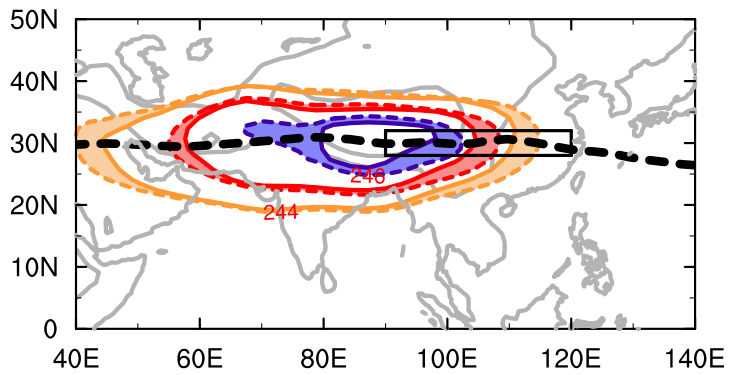

C
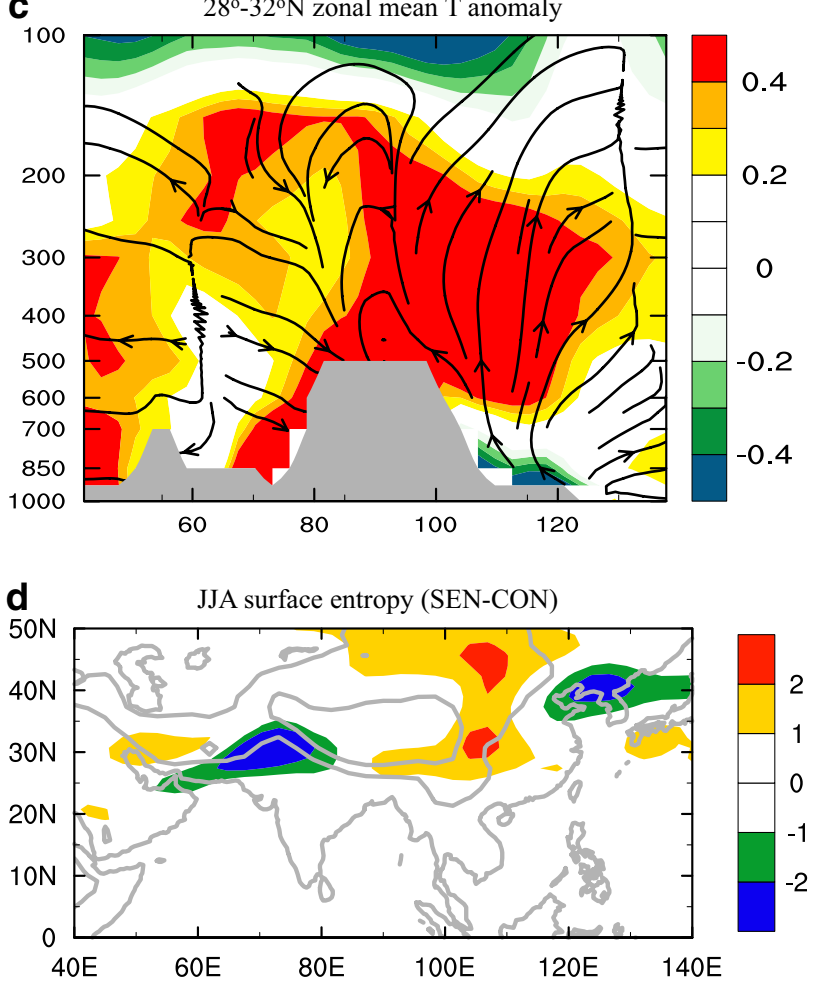

Fig. 6 Distributions of the JJA mean of a differences between the forcing experiment SEN and control experiment $\mathrm{CON}$ of rainfall (shading, unit: $\mathrm{mm} \mathrm{day}^{-1}$ ) and winds at $200 \mathrm{hPa}$ (arrow); b 200-400 hPa mass-weighted temperature in the SEN run (dashed) and CON run (solid); and the differences between SEN and CON of $\mathbf{c} 28^{\circ}-32^{\circ} \mathrm{N}$ zonal mean circulation (streamlines, vertical motion has been amplified by a factor of 500) and temperature (shading, unit: K); and d surface entropy (unit: K). The heavy dashed black curve in $\mathbf{b}$ denotes the ridgeline of the SAH at $200 \mathrm{hPa}$. The box in $\mathbf{a}$ and $\mathbf{b}$ indicates where the extra convective heating with a maximum of $3 \mathrm{~K} \mathrm{day}^{-1}$ at $500 \mathrm{hPa}$ is imposed in the SEN experiment a Wavelet Power

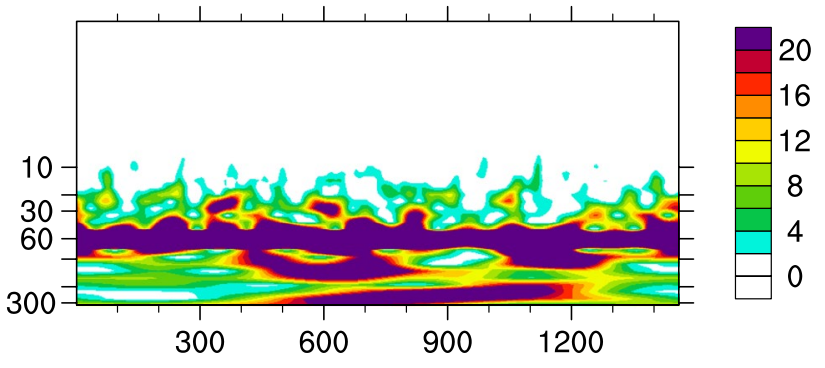

b Wavelet Significance

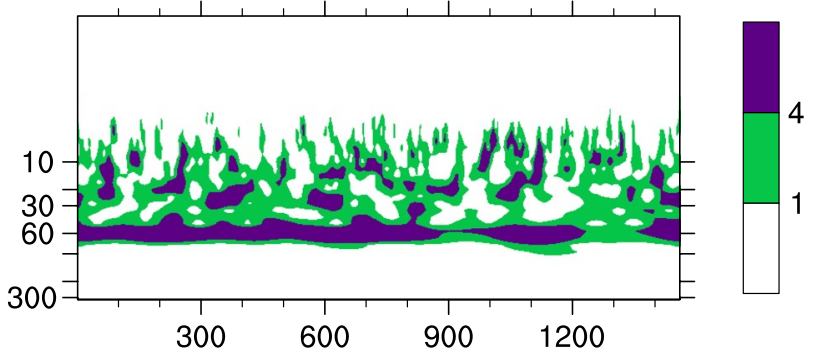

C Wavelet Power

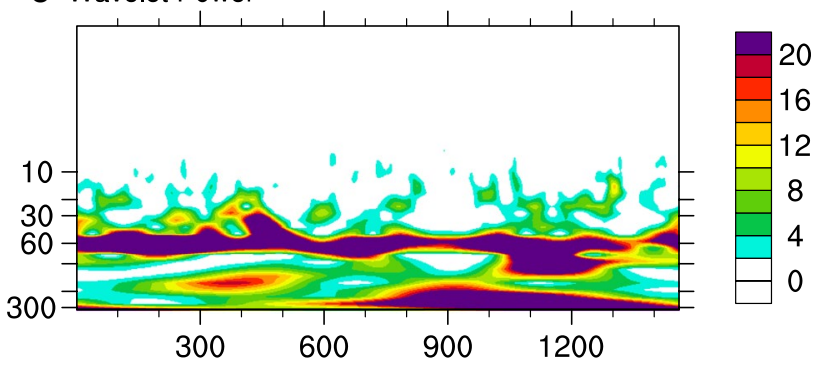

d Wavelet Significance

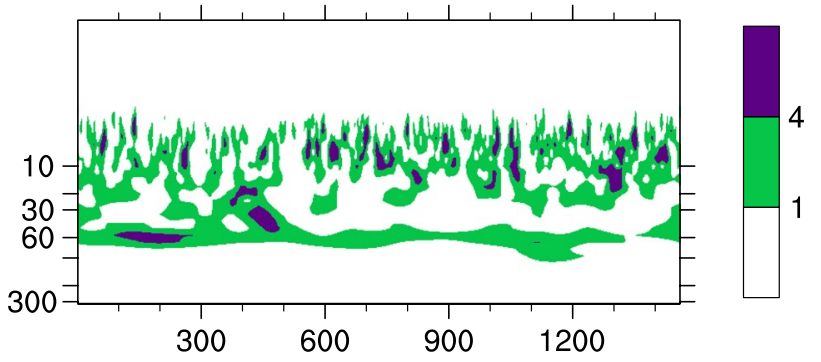

Fig. 7 Distributions in the PER experiment of wavelet power (a, c) and significance $(\mathbf{b}, \mathbf{d})$ for the $200-\mathrm{hPa}$ geopotential height in the forcing source region $\mathrm{S}\left(90^{\circ}-120^{\circ} \mathrm{E}, 28^{\circ}-32^{\circ} \mathrm{N}\right)(\mathbf{a}, \mathbf{b})$ and in the response region $\mathrm{R}\left(70^{\circ}-90^{\circ} \mathrm{E}, 28^{\circ}-32^{\circ} \mathrm{N}\right)(\mathbf{c}, \mathbf{d})$; abscissa is for integration day and coordinate is for period (unit: day)

are in good agreement with the analytical solution (9) and the data diagnosis presented in Fig. 4, and justify the proposed $\boldsymbol{T}-\boldsymbol{Q}_{Z}$ mechanism as presented in Fig. 5.

The response of surface entropy to the imposed extra monsoon latent heating is demonstrated in Fig. 6d. Despite the surface cooling in the east and warming in the west (Fig. 6c), the surface entropy is increased to the east of $90^{\circ} \mathrm{E}$ but decreased to its west, with the maximum located over the northern tip of India. This suggests a moistening 
of surface air in the east and drying in the west, in good coordination with the increased rainfall and air ascent in the east and decreased rainfall and air descent in the west.

Another sensitivity experiment PER is a perpetual July experiment that is based on the same SAMIL AGCM as used for the CON and SEN runs. However, the solar azimuth is fixed at July 15 throughout the integration, and a periodic thermal forcing term

$\left(\frac{\partial T}{\partial t}\right)_{O S C}=Q \cos (\omega t)$

is added to the thermodynamic equation in the same box region with the same vertical heating profile as described for SEN. An amplitude of the maximum heating rate $Q=5 \mathrm{~K} \mathrm{day}^{-1}$ at $500 \mathrm{hPa}$ and a frequency $\omega=(60 \text { day })^{-1}$ are assigned. Then the PER experiment is integrated for 4 years, and the results from the last 3 years (36 months) are retrieved for the following diagnosis. A wavelet power analysis and the corresponding significance diagnosis are applied to the 200-hPa geopotential height in the two experiments $\mathrm{CON}$ and PER in the forcing source region $\mathrm{S}\left(90^{\circ}-\right.$ $\left.120^{\circ} \mathrm{E}, 28^{\circ}-32^{\circ} \mathrm{N}\right)$ and the response region $\mathrm{R}\left(70^{\circ}-90^{\circ} \mathrm{E}\right.$, $\left.28^{\circ}-32^{\circ} \mathrm{N}\right)$. In the CON run, neither the forcing region $\mathrm{S}$ nor the response region $\mathrm{R}$ shows any apparent periodic oscillation (figures not show). However, in the PER run corresponding to the imposed periodic forcing, the wavelet power analysis at the 200-hPa geopotential height demonstrates that a significant 60-day oscillation signal exists not only in the forcing region S (Fig. 7a, b), but also in the response region R (Fig. 7c, d). Figure 8a presents the evolution of the normalized heating at $200 \mathrm{hPa}$ in the forcing region S. The normalized geopotential height at $200 \mathrm{hPa}$, the temperature averaged between 400 and $200 \mathrm{hPa}$, and the vertical velocity $\omega$-at $300 \mathrm{hPa}$ in the response region $\mathrm{R}$ are also shown. In the $\mathrm{S}$ region the heating evolution demonstrates a restricted 60-day oscillation. In the response region $\mathrm{R}$, the atmosphere demonstrates a well-defined and inherent 60-day oscillation too: in response to the positive/negative forcing in convective heating in $\mathrm{S}$, in the $\mathrm{R}$ region there appear positive/negative geopotential height at $200 \mathrm{hPa}$, a warm/cold air center in the upper troposphere between 400 and $200 \mathrm{hPa}$, and air descent/ascent at $300 \mathrm{hPa}$. The correlation coefficients between heating in the $\mathrm{S}$ region in the east and the geopotential height, temperature, and vertical motion in the $\mathrm{R}$ region in the west reach $0.80,0.67$, and 0.57 , respectively, exceeding the $99 \%$ significance level (0.542). While the vertical air motion in the west responds almost concurrently to the forcing in the east, there is a delay in the response of temperature and geopotential height in the $\mathrm{R}$ region compared to the forcing in the $S$ region (Fig. 8b). The correlation coefficients between the forcing and the responding temperatures with a delay of $2,4,6,8$, and 10 days are, respectively, 0.63 ,
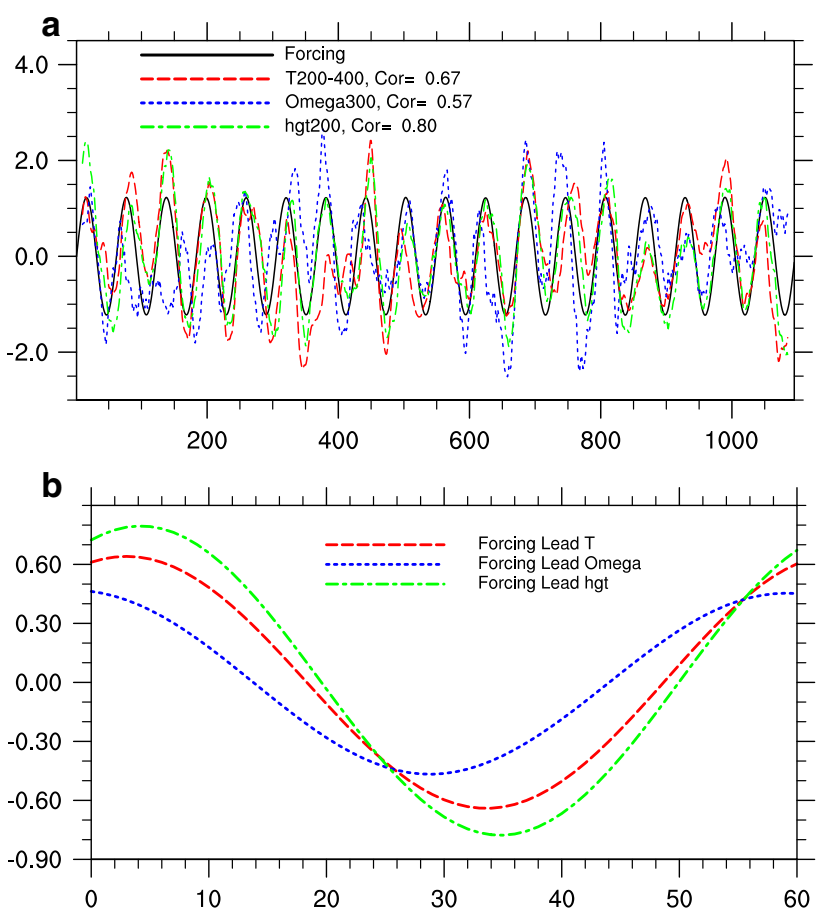

Fig. 8 Evolutions in the PER experiment of the normalized 200$500 \mathrm{hPa}$ mass-weighted mean heating in the forcing source region $\mathrm{S}$ (black solid), and the geopotential height at $200 \mathrm{hPa}$ (green dasheddotted), the 200-400 hPa mass-weighted temperature (red dashed), and pressure vertical motion at $300 \mathrm{hPa}$ (blue dotted) in the response region $\mathrm{R}(\mathbf{a})$; and the corresponding time-lag correlations between the forcing in region $\mathrm{S}$ and those in the response region $\mathrm{R}$ (b). A 20-day running mean has been used on the original data to filter out highfrequency noise

$0.67,0.68,0.66$, and 0.61 . These results highlight the significance of the circulation response to the monsoon rainfall: an oscillating rainfall anomaly of the ASM in return can force a corresponding oscillation in the atmospheric circulation.

To see the characteristics of the atmospheric circulation response to the exerted convective heating in the source region, we produce the composite crosssections averaged between $28^{\circ}$ and $32^{\circ} \mathrm{N}$ of the zonal circulation and temperature deviation from their $\left(40^{\circ}-140^{\circ} \mathrm{E}\right)$ means for the warm phase, mean state, cold phase, and the difference between the warm and cold phases. The response structures for the delays of $2,4,6,8$, and 10 days with respect to the forcing are similar to those of the simultaneous response. The composite results of the simultaneous response are presented in Fig. 9. The $\boldsymbol{T}-\boldsymbol{Q}_{Z}$ mechanism and the associated secondary circulation are prominent in all the zonal cross sections along the ridgeline of the SAH. In all phases of the oscillation, the area to the east of $80^{\circ} \mathrm{E}$ is characterized by air ascent, warm in the lower troposphere and cold in the upper troposphere. These are typical features of monsoon convection. The warmth in the lower layer is caused 

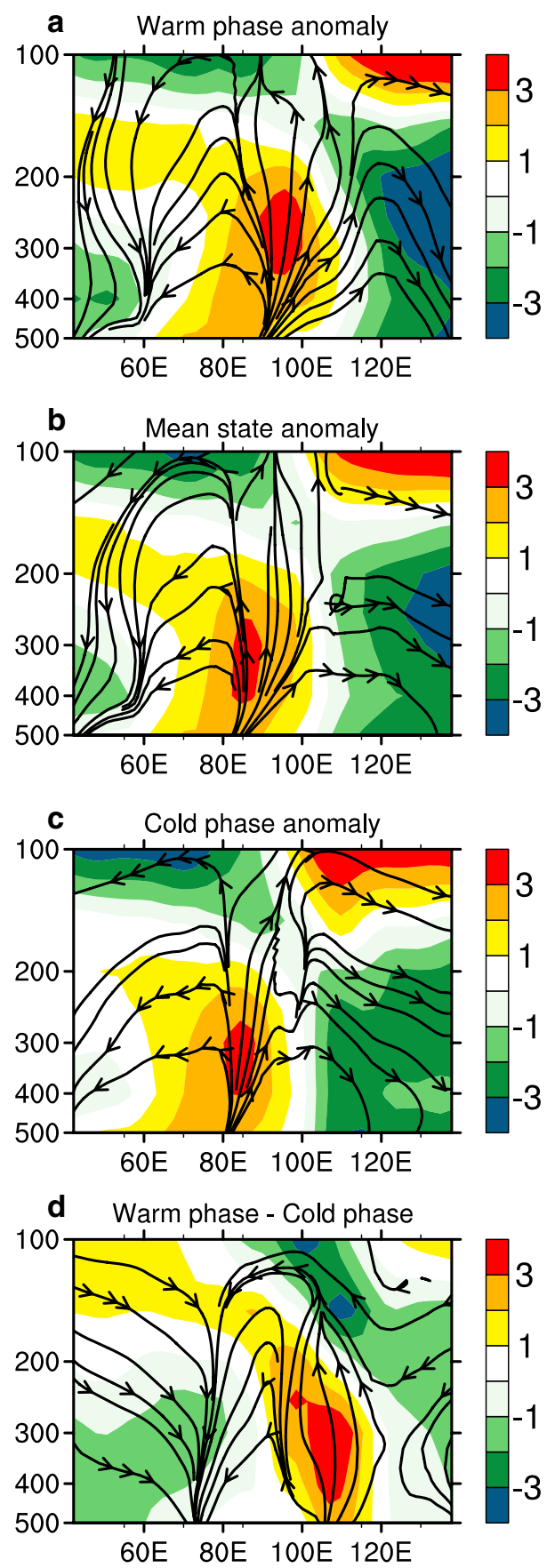

Fig. $928^{\circ}-32^{\circ} \mathrm{N}$ mean cross sections of zonal circulation (streamline) and temperature deviations (shading, unit: ${ }^{\circ} \mathrm{C}$ ) from the corresponding zonal means in $40^{\circ}-140^{\circ} \mathrm{E}$ produced from the PER experiment in a warm phase; $\mathbf{b}$ mean state; $\mathbf{c}$ cold phase; and $\mathbf{d}$ difference between (a) and (c)

by the convective latent heating, and the cold in the upper layer is a consequence of the overshooting of deep convection (Wu and Liu 2000). The upper boundary of the $2{ }^{\circ} \mathrm{C}$ warm region in the source region is located at $200 \mathrm{hPa}$ in the mean case (Fig. 9 b) but is higher up in the warm
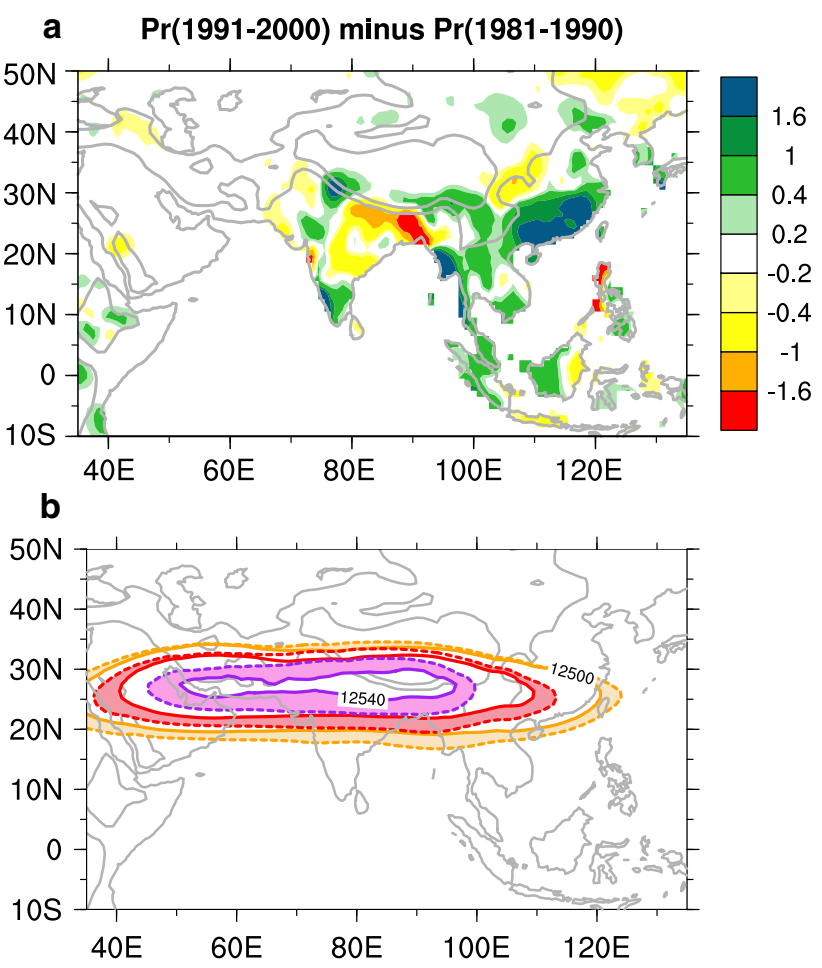

C ERA40 JJA upper-level temperature

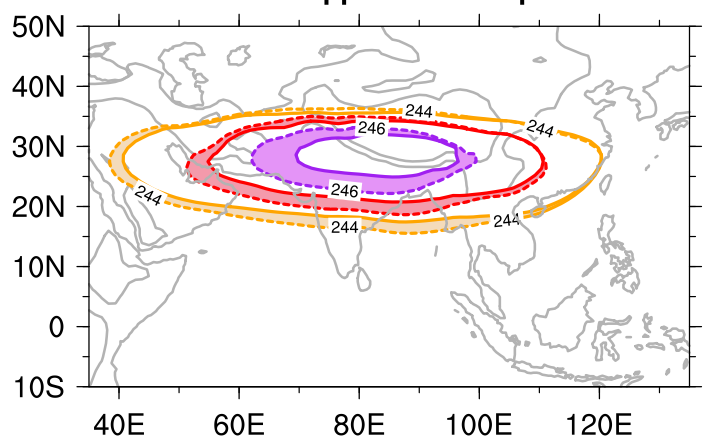

Fig. 10 Decadal changes in JJA mean climate between the periods (1991-2000) and (1981-1990) of a precipitation based on the PREC/L dataset (unit: $\mathrm{mm} \mathrm{day}{ }^{-1}$ ); b 200-hPa geopotential height (unit: gpm) and $\mathbf{c}$ the $200-400 \mathrm{hPa}$ mass-weighted temperature (unit: $\mathrm{K})$ based on ERA40 reanalysis. The solid and dashed curves in $\mathbf{b}$ and c denote, respectively, the 1981-1990 and 1991-2000 means

phase (Fig. 9a) and lower down in the cold phase (Fig. 9c). In contrast, the area to the west of $80^{\circ} \mathrm{E}$ is characterized by air descent, warm in the upper troposphere and cold in the mid troposphere. The cold in the lower layer must be due mainly to radiation cooling, and the warmth in the upper layer corresponds to the UTTM as discussed above. The intensity of the UTTM is strongest in the warm phase (Fig. 9a) and weakest in the cold phase (Fig. 9c). This implies that the circulation variation in the western region is tightly linked to the convective forcing in the source region to the east. As presented in Fig. 9d, the configuration 
of the difference is pretty similar to the schematic diagram (Fig. 5) inferred from theoretical analysis. Because the forced diabatic heating was imposed to the east of $90^{\circ} \mathrm{E}$, the separation between air ascent and descent is located by $90^{\circ} \mathrm{E}$ as well, again in good coordination with the results obtained by Rodwell and Hoskins (2001). Results from these experiments depict a well-developed $\boldsymbol{T}-\boldsymbol{Q}_{\boldsymbol{Z}}$ diagram and show that enhanced convective heating in the forcing region not only causes local tropospheric warming, but also forces a UTTM to its west.

\section{Implication for regional climate change}

During the last two decades of the twentieth century, summertime rainfall over South China has increased, due mainly to the weakening of TP thermal forcing (Duan and Wu 2008; Duan et al. 2011, 2012; Liu et al. 2012b). According to the above $\boldsymbol{T}-\boldsymbol{Q}_{Z}$ mechanism, the intensification of the monsoon rainfall in South China should exert significant influence on regional climate change, at least in the Asian monsoon area. Figure 10 shows the differences between the periods (1991-2000) and (1981-1990) of the JJA mean precipitation (a), geopotential height at $200 \mathrm{hPa}$ (b), and the UTTM (c). Along the latitude band of $24^{\circ}-$ $30^{\circ} \mathrm{N}$ where the $\mathrm{SAH}$ is seated (b), there is increased precipitation to the east of $90^{\circ} \mathrm{E}$ over the southeastern TP and southern China, but decreased precipitation to the west of $90^{\circ} \mathrm{E}$ over northeastern India in the last decade of the twentieth century compared to the previous decade (Fig. 10a). During the same period, the SAH is enhanced: the areas encircled by the $12,540,12,520$, and 12,500 dgpm contours at $200 \mathrm{hPa}$ are all increased (Fig. 10b). At the same time, the intensity of the UTTM increases, and its coverage expands remarkably (Fig. 10c). The area encircled by $246 \mathrm{~K}$ is about double, and the areas encircled by 245 and $244 \mathrm{~K}$ are also enlarged, in good correspondence with the increased precipitation over the area to the east of $90^{\circ} \mathrm{E}$.

Figure 11 shows the climate changes in different elements in the ASM regions. For this purpose, the evolutions from 1981 to 2002 of JJA mean climate elements are produced in different monsoon regions, and a 5-year running mean smoother is applied to the original dataset to weaken the interannual signals. A careful scrutiny of these time series reveals that their changes are very well organized indeed and can be interpreted using the $\boldsymbol{T}-\boldsymbol{Q}_{Z}$ mechanism just developed. During the period 1984-2000, the sensible heating averaged over the TP $\left(80^{\circ}-100^{\circ} \mathrm{E}, 26^{\circ}-36^{\circ} \mathrm{N}\right)$ decreases from 33 to $27 \mathrm{~W} \mathrm{~m}^{-2}$ (Fig. 11a). Because the TP surface sensible heating is an important driving force of the East ASM (Liu et al. 2012b; Wu and Zhang 1998; Wu et al. 2007, 2012a, b), the weakening of the TP forcing should result in a weakened low-layer southerly over East
Asia, with intensified precipitation being confined to South China. Consequently, the monsoon rainfall in the source region $\mathrm{S}^{*}\left(\right.$ Pr_east: $90^{\circ}-120^{\circ} \mathrm{E}, 24^{\circ}-28^{\circ} \mathrm{N}$ ) increases during the same period (Fig. 11b). The source region $\mathrm{S}^{*}$ defined here for reanalysis is shifted four degrees southward relative to the aforementioned source region $\mathrm{S}$ for modeling diagnoses because the ridgeline of the $\mathrm{SAH}$ is located by $26^{\circ}-27^{\circ} \mathrm{N}$ in reanalysis, but by $30^{\circ} \mathrm{N}$ in the model, so there is a southward shifting of three to four degrees. As discussed above, the increasing latent heat release in the source region $\mathrm{S}^{*}$ causes the intensifying SAH (Hgt_200, Fig. 11c) and UTTM averaged between 200 and $400 \mathrm{hPa}$ (Up_T, Fig. 11d) to its west in the response region $\mathrm{R}_{1}\left(70^{\circ}-\right.$ $\left.90^{\circ} \mathrm{E}, 24^{\circ}-28^{\circ} \mathrm{N}\right)$. According to (6), the intensification of the monsoon in the source region should also cause a local increase in the northerly at $200 \mathrm{hPa}$ (v_200 East, Fig. 11f) and the southerly at $700 \mathrm{hPa}$ (v_700 East, Fig. 11h). Further westward in the response region $\mathrm{R}_{2}\left(50^{\circ}-80^{\circ} \mathrm{E}, 24^{\circ}-28^{\circ} \mathrm{N}\right)$, the strengthening SAH and the UTTM should result in an increasing southerly at $200 \mathrm{hPa}$ (v_200 West, Fig. 11e) and a northerly at $700 \mathrm{hPa}$ (v_700 West, Fig. $11 \mathrm{~g}$ ) there, and the reduction of local rainfall as shown in Fig. 10a.

The applicability of the mechanism sketched in Fig. 5 to local interannual climate variability is also verified by calculating the corresponding correlation coefficients. For this purpose, the original datasets from ERA40 JJA mean climate elements are used, and the results are presented in Table 1. The rainfall in the source region $\mathrm{S}^{*}$ (Pr_east) is highly and significantly correlated with the UTTM (0.97), the SAH (0.94) in Region $\mathrm{R}_{1}$, and the meridional wind at $200 \mathrm{hPa}$ in the source region $\mathrm{S}^{*}(-0.95)$ and in the response region $R_{2}(0.67)$. These indicate that at an interannual timescale, anomalous monsoon rainfall can affect regional atmospheric circulation as well.

These results based on reanalysis data thus demonstrate that the different regional climate change or variation signals detected in different regions in Asia are dynamically well organized into a $\boldsymbol{T}-\boldsymbol{Q}_{Z}$ pattern as presented by the schematic diagram shown in Fig. 5.

\section{Discussion and conclusion}

The classical dynamics has demonstrated that in response to an axisymmetric diabatic heating, the atmospheric circulation adopts two distinct regimes: the TE regime in extra-tropics and the AMC regime in tropics, and in the upper troposphere the maximum temperature and geopotential height should be located in subtropics. It is demonstrated in this study that the longitude location of the summertime upper-tropospheric maximum temperature is a consequence of the atmospheric circulation response to the atmospheric diabatic heating along the subtropics, and presents a $\boldsymbol{T}-\boldsymbol{Q}_{\boldsymbol{Z}}$ relation: a warm 
a TP Surface Sensible Heat

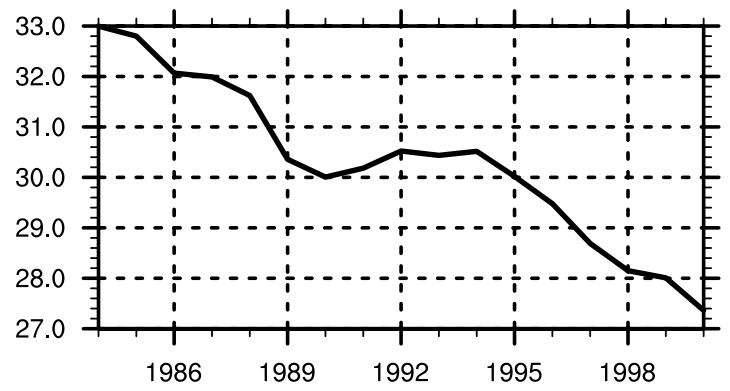

c Hgt_200: Geopotential in $\mathrm{R}_{1}$

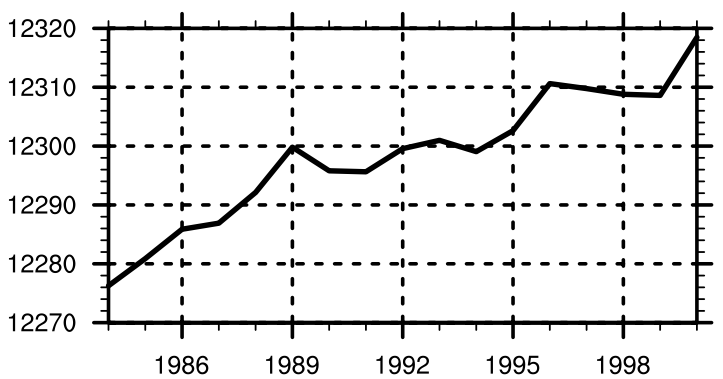

e v_200 West: wind in $R_{2}$

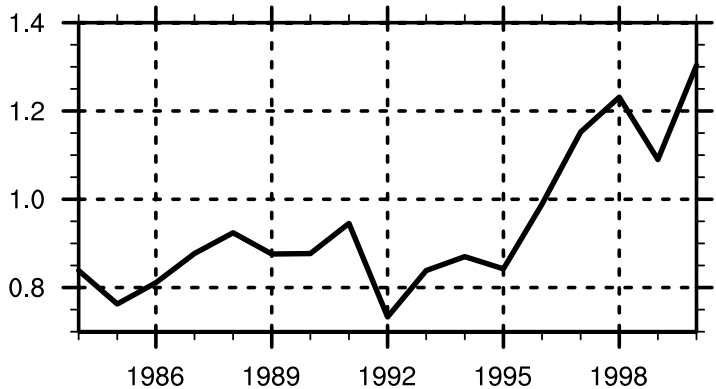

g $\quad$ __700 West: wind in $\mathrm{R}_{2}$

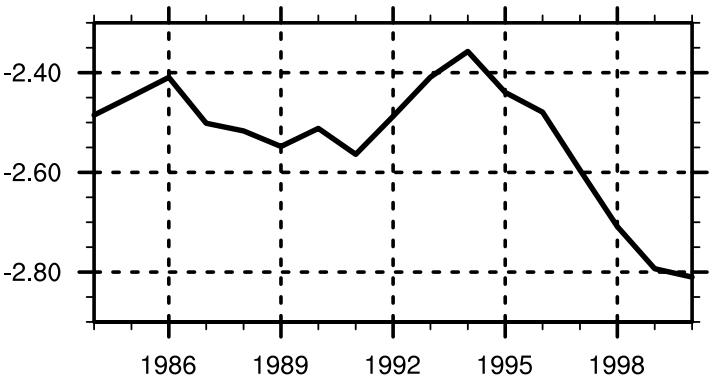

Fig. 11 Evolution from 1984 to 2000 of the JJA mean based on the ERA40 reanalysis of a surface sensible heat flux on the TP region $\left(80^{\circ}-100^{\circ} \mathrm{E}, 26^{\circ}-36^{\circ} \mathrm{N}\right.$, unit: $\left.\mathrm{W} \mathrm{m} \mathrm{m}^{-2}\right)$; b precipitation in the forcing source region $\mathrm{S}^{*}\left(\mathrm{Pr} \_\right.$east: $90^{\circ}-120^{\circ} \mathrm{E}, 24^{\circ}-28^{\circ} \mathrm{N}$, unit: $\mathrm{mm}$ day $\left.{ }^{-1}\right)$; c $200 \mathrm{hPa}$ geopotential height in the response region $\mathrm{R}_{1}$ (hgt_200:

temperature center is located between a monsoon heating in its east and a longwave radiation cooling in its west; whereas a cold temperature center is located between a monsoon b Pr_east: Rainfall in $\mathrm{S}^{*}$

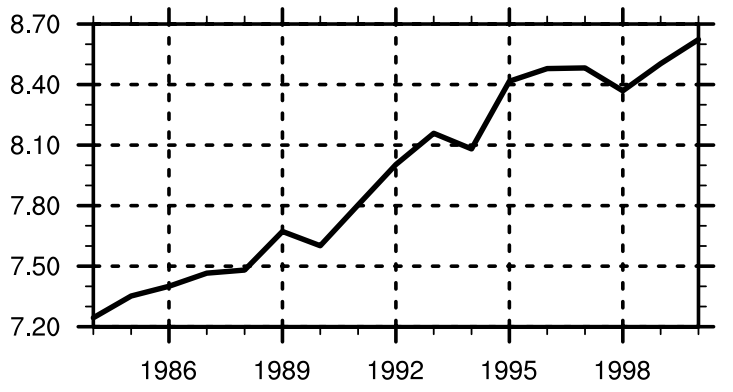

d Up_T: 200-400 Temperature in $\mathrm{R}_{1}$

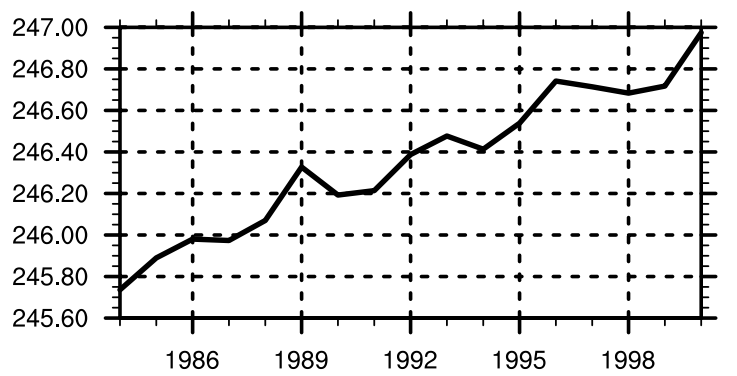

f v_200 East: wind in S*

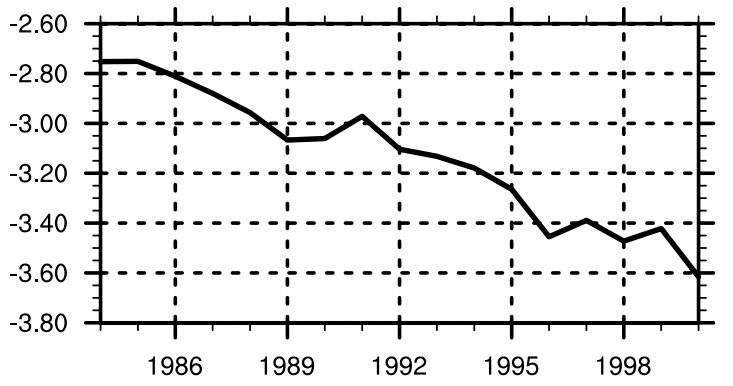

h v_700 East: wind in S*

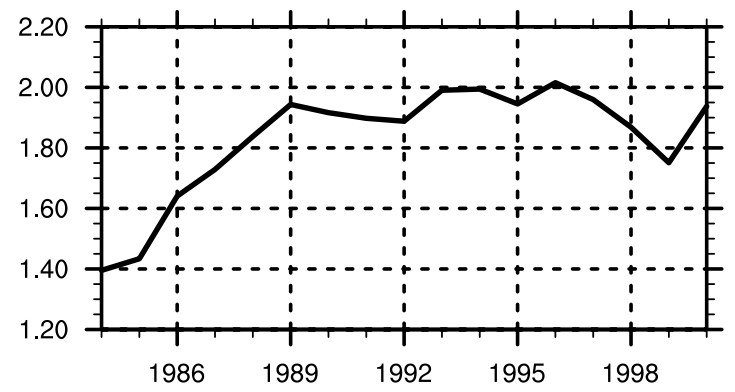

$70^{\circ}-90^{\circ} \mathrm{E}, 24^{\circ}-28^{\circ} \mathrm{N}$, unit: dgpm); d $200-400 \mathrm{hPa}$ mass-weighted temperature in $\mathrm{R}_{1}$ (Up_T, unit: $\mathrm{K}$ ), $200 \mathrm{hPa}$ meridional wind $\mathrm{e}$ in the response region $R_{2}$ (v_200 West: $50^{\circ}-80^{\circ} \mathrm{E}, 24^{\circ}-28^{\circ} \mathrm{N}$ ) and $\mathbf{f}$ in $\mathrm{S}^{*}$ (v_200 East, unit: $\mathrm{m} \mathrm{s}^{-1}$ ), and $700 \mathrm{hPa}$ meridional wind $\mathbf{g}$ in $\mathrm{R}_{2}$ (v_700 West, unit: $\mathrm{m} \mathrm{s}^{-1}$ ) and $\mathbf{h}$ in $\mathrm{S}^{*}$ (v_700 East, unit: $\mathrm{m} \mathrm{s}^{-1}$ )

heating in its west and a longwave radiation cooling in its east. A $\boldsymbol{T}-\boldsymbol{Q}_{Z}$ mechanism is thus delineated for the longitude location of the UTTM over North India: In summertime in 
Table 1 Correlation coefficients at the interannual timescale among those variables presented in Fig. 11: 200-400 hPa mass-weighted temperature (Up_T) in the response region $\mathrm{R}_{1}\left(70^{\circ}-90^{\circ} \mathrm{E}, 24^{\circ}-28^{\circ} \mathrm{N}\right)$, $200 \mathrm{hPa}$ geopotential height in $\mathrm{R}_{1}$ (Hgt_200), precipitation in the forcing source region $\mathrm{S}^{*}$ (Pr_east: $90^{\circ}-120^{\circ} \mathrm{E}, 24^{\circ}-28^{\circ} \mathrm{N}$ ), and the 200-hPa meridional wind in $\mathrm{S}^{*}$ (v_200_East) and in the response region $\mathrm{R}_{2}\left(\mathrm{v} \_200 \_\right.$West: $50^{\circ}-80^{\circ} \mathrm{E}, 24^{\circ}-28^{\circ} \mathrm{N}$ )

\begin{tabular}{lrrrrr}
\hline $\begin{array}{l}\text { Correlation } \\
\text { coefficient }\end{array}$ & UP_T & Hgt_200 & Pr_east & v_200_east & v_200_west \\
\hline Up_T & 1.0 & & & & \\
Hgt_200 & 0.99 & 1.0 & & & \\
Pr_east & 0.97 & 0.94 & 1.0 & & \\
v_200_east & -0.98 & -0.97 & -0.95 & 1.0 & \\
v_200_west & 0.72 & 0.73 & 0.67 & -0.79 & 1.0 \\
\hline
\end{tabular}

The 95 and $99 \%$ significance levels are, respectively, 0.51 and 0.64

the subtropics where the relative vorticity advection is weak, strong latent heat released by the Asian monsoon can generate a strong vertical gradient of diabatic heating, resulting in a vertical northerly shear in situ. The UTTM and the associated upper tropospheric anticyclone SAH aloft thus develop to the west of the latent heating so that the eastward zonaltemperature decrease matches the vertical northerly shear in the monsoon region and the thermal wind balance is maintained. Over western Eurasia, strong surface sensible heating and longwave radiation cooling in the free atmosphere produce vertical southerly shear, and the UTTM develops on the eastern end of the radiation cooling region. Thus, the UTTM is generated to the west of monsoon convective heating and to the east of radiation cooling.

It is shown that the $\boldsymbol{T}-\boldsymbol{Q}_{Z}$ model developed here is based on the potential vorticity (PV) theory and is different from the original Gill's model. In order to keep consistency of the Gill's model with the PV theory, it is demonstrated that the originally defined "heating rate" $\boldsymbol{Q}$ in the continuity equation of the Gill's model should be replaced by a vorticity forcing which is proportional to the vertical gradient of diabatic heating, i.e., $\partial \boldsymbol{Q} / \partial z$ z. Furthermore, if the Rayleigh friction and Newtonian cooling in the Gill's model are removed, the system becomes identical to the PV system employed in this study and can be used to study the upper tropospheric dynamics.

Results from numerical sensitivity experiments show that enhancing the convective heating to the east of $90^{\circ} \mathrm{E}$ along the SAH ridgeline can intensify the SAH and UTTM to its west, and imposing a periodic convective latent heating in this source region can also induce periodic oscillations in the geopotential height, vertical air descent, and temperature to the west with the same frequency and a similar phase. Diagnoses based on the ERA40 reanalysis data also show that at either an interannual or decadal scale, the change and variation of the Asian summer rainfall in the forcing region are significantly correlated with the change and variation of the SAH, UTTM, and vertical motion in the response region to the west. All these results justify our conclusion that the appearance and variation of the summertime upper tropospheric warm center situated over North India can to a large extent be attributed to the strong convective latent heating associated with the Asian monsoon rainfall over the area southeast of the TP and over South China, and also to the longwave radiation cooling over the western Eurasia.

The $\boldsymbol{T}-\boldsymbol{Q}_{Z}$ mechanism identified in this study highlights the inherent structure of the Asian monsoon system and the significant monsoon feedback on the circulation. However, the monsoon system is an open-dissipative system. When its variability is studied, the impacts of external forcing such as that of the ocean, the land-sea thermal contrast, and the thermal forcing of the Iranian Plateau and TP should be taken into account.

The current study focuses on the allocation of the upper tropospheric warm center and the monsoon latent heating along the subtropics without considering the whole structure and configuration of the UTTM. Because the summertime large-scale circulation in the subtropics is a consequence of multiscale forcing-including continental-scale LOSECOD thermal forcing, regional-scale mountain forcing, and local-scale sea-breeze forcing - and because the UTTM is closely tied to the SAH, which links the westerly in the mid-latitudes to the easterly in the tropics, a full understanding of the formation and variation of the UTTM will require great effort and deserves further study.

Acknowledgments We would like to thank Dr. Schneider and the anonymous reviewers for their constructive suggestions, which were indispensable for the improvement of the manuscript, and to Mr. Haiyang Yu and Mr. Xiaofei Wu for plotting Fig. 5. This study was jointly funded by the Third Tibetan Plateau Scientific Experiment GYHY201406001, National Basis Research Program of China (2014CB953904), the National Natural Science Foundation of China Projects (40925015, 41275088, 91437219, 41405091). The second author is also funded by State Key Laboratory of Loess and Quaternary Geology (SKLLQG1216).

Open Access This article is distributed under the terms of the Creative Commons Attribution License which permits any use, distribution, and reproduction in any medium, provided the original author(s) and the source are credited.

\section{References}

Bao Q, Wu GX, Liu YM, Yang J, Wang ZZ, Zhou TJ (2010) An introduction to the coupled model FGOALS1.1-s and its performance in East Asia. Adv Atmos Sci 27(5):1131-1142

Bao Q, Lin PF, Zhou TJ, Liu YM, Yu YC, Wu GX et al (2013) The flexible global ocean-atmosphere-land system model version: FGOALS-s2. Adv Atmos Sci. doi:10.1007/s00376-012-2113-9

Boos WR, Kuang ZM (2010) Dominant control of the South Asian monsoon by orographic insulation versus plateau heating. Nature 463:218-223 
Boos WR, Kuang ZM (2013) Sensitivity of the South Asian monsoon to elevated and non-elevated heating. Sci Rep 3:1192. doi:10.1038/srep01192

Chen LX (1985) The variation of the atmospheric heat source and the budget of atmospheric energy on the QingHai-Xizang Plateau during summer 1979. Acta Meteorol Sin 43:1-12

Chen M, Xie P, Janowiak JE, Arkin PA (2002) Global land precipitation: a 50-yr monthly analysis based on gauge observations. J Hydrometeorol 3:249-266

Duan AM, Wu GX (2008) Weakening trend in the atmospheric heat source over the Tibetan Plateau during recent decades. Part I: Observations. J Clim 21:3149-3164

Duan AM, Li F, Wang MR, Wu GX (2011) Persistent weakening trend in the spring sensible heat source over the Tibetan Plateau and its impact on the Asian summer monsoon. J Clim 24:5671-5682

Duan AM, Wang MR, Lei YH, Cui YF (2012) Trends in summer rainfall over China associated with the Tibetan Plateau sensible heat source during 1980-2008. J Clim. doi:10.1175/ JCLI-D-11-00669.1

Emanuel KA (1991) A scheme for representing cumulus convection in large-scale models. J Atmos Sci 48(21):2313-2329

Emanuel KA, Neelin JD, Bretherton CS (1994) On large-scale circulations in convecting atmospheres. Quart J R Meteorol Soc 120:1111-1143

Ertel H (1942) Ein neuer hydrodynamische wirbdsatz. Meteorol Z Braunschw 59:277-281

Flohn H (1957) Large-scale aspects of the summer monsoon in South and East Asia. J Meteorol Soc Jpn 75:180-186

Gill AE (1980) Some simple solutions for heat-induced tropical circulation. Quart J R Meteorol Soc 106:447-462

Hahn DG, Manabe S (1975) The role of mountains in the south Asian monsoon circulation. J Atmos Sci 32(8):1515-1541

Held IM, Hou AY (1980) Nonlinear axially symmetric circulations in a nearly inviscid atmosphere. J Atmos Sci 37:515-533

Hoskins BJ (1987) Diagnosis of forced and free variability in the atmosphere. In: Bracknell HC (ed) Atmospheric and oceanic variability. James Glaisher House, Bracknell, pp 57-73

Hoskins BJ, Mclntyre ME, Robertson AW (1985) On the use and significance of isentropic potential vorticity maps. Quart J R Meteorol Soc 111:877-946

Krishnamurti TN (1973) Tibetan high and upper tropospheric tropical circulation during northern summer. Bull Am Meteorol Soc 54:1234-1249

Li C, Yanai M (1996) The onset and interannual variability of the Asian summer monsoon in relation to land-sea thermal contrast. J Clim 9:358-375

Liu YM, Wu GX, Liu H, Liu P (1999) Impacts of spatial differential heating on the formation and variation of the subtropical anticyclone, III. Condensation latent heating and South Asian high and the subtropical anticyclone over western Pacific. Acta Meteorol Sin 57:525-538

Liu YM, Wu GX, Liu H, Liu P (2001) Condensation heating of the Asian summer monsoon and the subtropical anticyclone in the Eastern Hemisphere. Clim Dyn 17:327-338

Liu YM, Hoskins BJ, Blackburn M (2007) Impact of Tibetan orography and heating on the summer flow over Asia. J Meteorol Soc Jpn (Special 125th Anniversary Issue, Invited Review Articles) 85B:1-19

Liu BQ, He JH, Wang LJ (2012a) On a possible mechanism for southern Asian convection influencing the South Asian high establishment during winter to summer transition. J Trop Meteorol 18(4):473-484

Liu YM, Wu GX, Hong JL, Dong BW, Duan AM, Bao Q, Zhou LJ (2012b) Revisiting Asian monsoon formation and change associated with Tibetan Plateau forcing: II. Change. Clim Dyn 39(5):1183-1195. doi:10.1007/s00382-012-1335-y
Liu BQ, Wu GX, Mao JY, He JH (2013a) Genesis of the South Asian high and its impact on the Asian summer monsoon onset. J Clim 26:2976-2991. doi:10.1175/JCLI-D-12-00286.1

Liu YM, Hu J, He B, Bao Q, Duan AM, Wu GX (2013b) Seasonal evolution of the subtropical anticyclones in a climate system model FGOALS-s2. Adv Atmos Sci 30(3):593-606. doi:10.1007/ s00376-012-2154-0

Luo HB, Yanai M (1983) The large-scale circulation and heat sources over the Tibetan Plateau and surrounding areas during the early summer of 1979. Part I: precipitation and kinematic analyses. Mon Weather Rev 111:922-944

Luo HB, Yanai M (1984) The large-scale circulation and heat sources over the Tibetan Plateau and surrounding areas during the early summer of 1979. Part II: heat and moisture budgets. Mon Weather Rev 112:966-989

Mason RB, Anderson CE (1963) The development and decay of the 100-mb summertime anticyclone over southern Asia. Mon Weather Rev 91:3-12

Peng YP, He JH, Chen LX, Zhang B (2014) A study on the characteristics and effect of the low-frequency oscillation of the atmospheric heat source over the eastern Tibetan Plateau. J Trop Meteorol 20(1):17-25

Plumb RA, Hou AY (1992) The response of a zonally symmetric atmosphere to subtropical forcing: threshold behavior. J Atmos Sci 49: 1790-1799

Prive NC, Plumb RA (2007a) Monsoon dynamics with interactive forcing. Part I: axisymmetric studies. J Atmos Sci 64:1417-1430

Prive NC, Plumb RA (2007b) Monsoon dynamics with interactive forcing. Part II: impact of eddies and asymmetric geometrics. J Atmos Sci 64:1431-1442

Rodwell MR, Hoskins BJ (1996) Monsoon and the dynamics of deserts. Quart J R Meteorol Soc 122:1385-1404

Rodwell MR, Hoskins BJ (2001) Subtropical anticyclones and summer monsoon. J Clim 14:3192-3211

Sardeshmukh PD, Hoskins BJ (1985) Vorticity balances in the tropics during 1982-83 El Nino-southern oscillation event. Quart J R Meteorol Soc 111:261-278

Schneider EK (1977) Axially symmetric steady-state models of the basic state for instability and climate studies. Part II: nonlinear calculations. J Atmos Sci 34:280-296

Schneider EK (1987) A simplified model of the modified Hadley circulation. J Atmos Sci 44(22):3311-3328

Schneider EK, Lindzen RS (1976) A discussion of the parameterization of momentum exchange by cumulus convection. J Geophys Res 81:3158-3160

Schneider EK, Lindzen RS (1977) Axially symmetric steady-state models of the basic state for instability and climate studies. Part I: linearized calculations. J Atmos Sci 34(2):263-279

Smagorinsky J (1953) The dynamical influence of large scale heat sources and sinks on the quasi-stationary mean motions of the atmosphere. Quart J R Meteorol Soc 79:342-366

Tamura TK, Taniguchi K, Koike T (2010) Mechanism of upper tropospheric warming around the Tibetan Plateau at the onset phase of the Asian summer monsoon. J Geophys Res 115:D02106. doi:10. 1029/2008JD011678

Tao SY, Zhu FK (1964) The variation of $100 \mathrm{mb}$ circulation over South Asia in summer and its association with march and withdraw of West Pacific Subtropical High. Acta Meteorol Sin 34:385-395

Uppala SM, Kållberg PW, Simmons AJ, Andrae U, Bechtold V, Fiorino M, Woollen J (2005) The ERA-40 reanalysis. Quart J R Meteorol Soc 131(612):2961-3012

Wang B, Lin H (2002) Rainy season of the Asian-Pacific summer monsoon. J Clim 15:386-398

Wu GX, Liu YM (2000) Thermal adaptation, overshooting, dispersion and subtropical anticyclone. I. Thermal adaptation and overshooting. Chin J Atmos 24:433-446 
Wu GX, Liu YM (2003) Summertime quadruplet heating pattern in the subtropics and the associated atmospheric circulation. Geophys Res Lett 30(5):1201. doi:10.1029/2002GL016209

Wu GX, Zhang YS (1998) Tibetan Plateau forcing and the timing of the monsoon onset over South Asia and the South China Sea. Mon Weather Rev 126:913-927

Wu GX, Liu YM, Liu P (1999) Impacts of spatial differential heating on the formation and variation of the subtropical anticyclone. I. Scale analysis. Acta Meteorol Sin 57:257-263

Wu GX, Liu YM, Liu P, Ren RC (2002) Relation between the zonal mean subtropical anticyclone and the sinking arm of the Hadley cell. Acta Meteorol Sin 61:635-636

Wu TW, Liu P, Wang ZZ, Liu YM, Yu RC, Wu GX (2003) The performance of atmospheric component model (R42L9.0) of GOALS/ LASG. Adv Atmos Sci 20(5):726-742

Wu GX, Liu YM, Wang TM, Wan RJ, Liu X, Li WP, Wang ZZ, Zhang Q, Duan AM, Liang XY (2007) The influence of mechanical and thermal forcing by the Tibetan Plateau on Asian climate. J Hydrometeorol 8:770-789

Wu GX, Liu YM, Zhu X, Li W, Ren R, Duan A, Liang X (2009) Multi-scale forcing and the formation of subtropical desert and monsoon. Ann Geophys 27:3631-3644

Wu GX, Liu YM, He B, Bao Q, Duan AM, Jin FF (2012a) Thermal controls on the Asian summer monsoon. Sci Rep 2:404. doi:10.1038/srep00404
Wu GX, Liu YM, Dong BW, Liang XY, Duan AM, Bao Q, Yu JJ (2012b) Revisiting Asian monsoon formation and change associated with Tibetan Plateau forcing: I. Formation. Clim Dyn 39(5):1169-1181. doi:10.1007/s00382-012-1334-z

Xie SP, Saiki N (1999) Abrupt onset and slow seasonal evolution of summer monsoon in an idealized GCM simulation. J Meteorol Soc Jpn 77:949-968

Yanai M, Li CF (1996) Seasonal and interannual variability of atmospheric heating. Eighth conference on air-sea interaction and symposium on GOALS. 28 January-2 February, Atlanta GA. Am Meteorol Soc 102-106

Yanai M, Esbensen S, Chu JH (1973) Determination of bulk properties of tropical cloud clusters from large-scale heat and moisture budgets. J Atmos Sci 30(4):611-627

Yanai M, Li CF, Song ZS (1992) Seasonal heating of the Tibetan Plateau and its effects on the evolution of the Asian summer monsoon. J Meteorol Soc Jpn 70(1):319-351

Ye DZ, Gao YX (1979) Meteorology of the Qinghai-Xizang Plateau. Chinese Science Press, Beijing (in Chinese)

Yeh TC, Lo SW, Chu PC (1957) The wind structure and heat balance in the lower troposphere over Tibetan Plateau and its surroundings. Acta Meteorol Sin 28:108-121

Zhang Q, Wu GX, Qian YF (2002) The bimodality of the $100 \mathrm{hPa}$ South Asia High and its relationship to the climate anomaly over East Asia in summer. J Meteorol Soc Jpn 80(4):733-744 